\title{
Subdiurnal Stratocumulus Cloud Fraction Variability and Sensitivity to Precipitation*
}

\author{
CASEy D. BURLEYSON \\ North Carolina State University, Raleigh, North Carolina, and Pacific Northwest National Laboratory, Richland, Washington \\ SANDRA E. YUTER \\ North Carolina State University, Raleigh, North Carolina
}

(Manuscript received 22 September 2014, in final form 12 December 2014)

\begin{abstract}
This paper presents an analysis of subtropical marine stratocumulus cloud fraction variability using a 30-min and $3^{\circ} \times 3^{\circ}$ cloud fraction dataset from 2003 to 2010 . Each of the three subtropical marine stratocumulus regions has distinct diurnal characteristics, but the southeast (SE) Pacific and SE Atlantic are more similar to each other than to the northeast (NE) Pacific. The amplitude and season-to-season diurnal cycle variations are larger in the Southern Hemisphere regions than in the NE Pacific. Net overnight changes in cloud fraction on $3^{\circ} \times 3^{\circ}$ scales are either positive or neutral $>77 \%$ of the time in the NE Pacific and $>88 \%$ of the time in the SE Pacific and SE Atlantic. Cloud fraction often increases to $100 \%$ by dawn when cloud fraction at dusk is $>30 \%$. In the SE Pacific and SE Atlantic, a typical decrease in cloud area (median $\leq-5.7 \times 10^{5} \mathrm{~km}^{2}$ ) during the day is equivalent to $25 \%$ or more of the annual-mean cloud deck area. Time series for $3^{\circ} \times 3^{\circ}$ areas where cloud fraction was $\geq 90 \%$ sometime overnight and $<60 \%$ at dawn, such as would result from nocturnal formation of pockets of open cells (POCs), only occur $1.5 \%, 1.6 \%$, and $3.3 \%$ of the time in the SE Pacific, SE Atlantic, and NE Pacific, respectively. Comparison of cloud fraction changes to ship-based radar and satellitederived precipitation intensity and area measurements shows a lack of sensitivity of cloud fraction to drizzle on time scales of $1-3 \mathrm{~h}$ and spatial scales of $100-300 \mathrm{~km}$.
\end{abstract}

\section{Introduction}

Subtropical marine stratocumulus clouds are important for the global radiation balance (Manabe and Strickler 1964; Hartmann et al. 1992; Klein and Hartmann 1993) and have proven to be difficult to accurately simulate in general circulation models (GCMs; Abel et al. 2010; Wyant et al. 2010; Medeiros et al. 2012; Wyant et al. 2014). These low, liquid-phase clouds form over cool ocean waters and beneath a regional-scale subsidence inversion. Marine stratocumulus clouds often occur in closed (unbroken cloud) and open (broken cloud) cellular planiforms (e.g., Atkinson and Zhang

\footnotetext{
* Supplemental information related to this paper is available at the Journals Online website.

Corresponding author address: Dr. Casey D. Burleyson, Pacific Northwest National Laboratory, P.O. Box 999/MS K9-24, Richland, WA 99352.

E-mail: casey.burleyson@pnnl.gov
}

1996; Stevens et al. 2005; Wood and Hartmann 2006; Wood et al. 2008).

Field observations (Stevens et al. 2003; Bretherton et al. 2004; Wood et al. 2011a; Mechoso et al. 2014) and modeling sensitivity studies (e.g., Bretherton and Wyant 1997; Savic-Jovcic and Stevens 2008; Wang and Feingold 2009; Mechem et al. 2012; Myers and Norris 2013) have revealed that a large number of physical processes can modify subtropical marine stratocumulus cloud fraction (CF) on a range of time scales. These include stability and inversion strength (Klein and Hartmann 1993; Wood and Bretherton 2006; Zhang et al. 2009; Myers and Norris 2013), subsidence (Zhang et al. 2009; Myers and Norris 2013), the diurnal cycle of radiative fluxes and decoupling in the boundary layer (Turton and Nicholls 1987; Duynkerke 1989; Betts 1990; Xiao et al. 2011; de Szoeke et al. 2012), mesoscale circulations (Atkinson and Zhang 1996), drizzle (vanZanten and Stevens 2005; Comstock et al. 2005; Wood and Hartmann 2006), near-surface outflow boundaries and density currents (Feingold et al. 2010; Terai 2011; Wilbanks 2013), aerosols (Albrecht 1989; Pincus and 
TABLE 1. A summary of some of the existing POC cases that have been discussed in the literature and the characteristics of when and where they were observed. Where possible, we note the time of POC formation given in the paper or otherwise estimate the time of formation from the data presented in the paper. Many of the cases do not have sufficient evidence to determine exactly when the POC formed. In these cases, we list the time frame over which they were analyzed. Some of the POC events are discussed in multiple papers. RF06, RF07, RF08, RF09, and RF13 correspond to NCAR C-130 research flight numbers during VOCALS-REx.

\begin{tabular}{lllll}
\hline \hline Paper and relevant figures/tables & \multicolumn{1}{c}{ Basin } & \multicolumn{1}{c}{ Date } & Analyzed/formed LT & \multicolumn{1}{c}{ Data sources } \\
\hline Stevens et al. 2005, Fig. 2 & SE Pacific & 19 Oct 2001 & Analyzed 0600-1200 & GOES visible reflectance, cloud radar \\
Stevens et al. 2005, Fig. 3 & NE Pacific & 11 Jul 2002 & Analyzed $~ 0730$ & GOES visible reflectance, lidar \\
vanZanten and Stevens 2005, Fig. 1 & NE Pacific & 11 Jul 2002 & Analyzed $~ 0730$ & GOES visible reflectance, cloud radar \\
Sharon et al. 2006, Fig. 1a & NE Pacific & 30 Jun 1987 & Analyzed $~ 1030$ & GOES visible reflectance \\
Sharon et al. 2006, Fig. 1b & NE Pacific & 16 Jul 1999 & Analyzed 0845 & GOES visible reflectance \\
Comstock et al. 2007, Fig. 13 & SE Pacific & 18 Oct 2001 & Formed 0345-0645 & GOES IR, precipitation radar \\
Wood et al. 2008, Figs. 4 and 5 & SE Pacific & 17 Oct 2001 & Formed 0500-0600 & GOES IR, ceilometer, cloud radar \\
Wood et al. 2008, Figs. 6 and 7 & SE Pacific & 16 Nov 2003 & Formed 0315 & GOES IR, ceilometer, cloud radar \\
Wood et al. 2011b, Fig. 2 (RF06) & SE Pacific & 27 Oct 2008 & Formed 2330-0530 & GOES IR \\
Terai et al. 2014, Table 1 (RF06) & SE Pacific & 28 Oct 2008 & Analyzed 0306-0805 & GOES IR, cloud radar \\
Terai et al. 2014, Table 1 (RF07) & SE Pacific & 31 Oct 2008 & Analyzed 0314-0619 & GOES IR, cloud radar \\
Terai et al. 2014, Table 1 (RF08) & SE Pacific & 2 Nov 2008 & Analyzed 0349-0706 & GOES IR, cloud radar \\
Terai et al. 2014, Table 1 (RF09) & SE Pacific & 4 Nov 2008 & Analyzed 0311-0614 & GOES IR, cloud radar \\
Terai et al. 2014, Table 1 (RF13) & SE Pacific & 13 Nov 2008 & Analyzed 1045-1453 & GOES IR, cloud radar \\
\hline
\end{tabular}

Baker 1994), boundary layer depth (Bretherton and Wyant 1997; Wood and Hartmann 2006; Mechem et al. 2012), and gravity waves (Allen et al. 2013).

Mesoscale transitions (in both directions) between high CF closed cells and low CF open cells can occur over a few hours (Stevens et al. 2005; Comstock et al. 2007; Wood et al. 2008, 2011b). When a small area of cloud (tens of kilometers wide) breaks up over a few hours within a larger closed-cell region, it is of high interest because the spatial and temporal scales of the cloud breakup can rule out several of the candidate processes that only vary on a larger space or longer time scales. Stevens et al. (2005) coined a specific term, "pockets of open cells" (POCs), to describe mesoscale regions of open-cellular cloud structures embedded within regions of closed-cellular cloud fields. Wood et al. (2008) were among the first to quantify the frequency of occurrence and environmental characteristics associated with POC formations. They used visual examination of satellite images to identify 23 POC formation events in the southeast (SE) Pacific during September and October 2001. This frequency of occurrence corresponds to one POC forming about every 2.7 days. Of the 23 POCs, 16 formed at night (Wood et al. 2008, their Fig. 10a). Nocturnal POCs are particularly interesting as these represent examples when cloud breakup occurs in the absence of shortwave (SW) radiative fluxes, which can induce cloud breakup during the day. Once POCs form, they may be resistant to closing up over a period of several days (Wood et al. 2008, 2011b; Berner et al. 2013).

Several examples of POC formation events appear in the literature (Table 1). These case studies have been used to implicate precipitation as the cause of cloud breakup in POC regions. Precipitation can act to remove aerosols and stabilize the subcloud layer (Stevens et al. 2005; Savic-Jovcic and Stevens 2008; Wang and Feingold 2009), and coalescence scavenging of aerosols via precipitation has been hypothesized to contribute to the maintenance of open-cellular structures (Wood et al. 2011b). The hypothesized relationships between aerosols, clouds, and precipitation and the formation of POCs were the basis of two of the four meteorological hypotheses that motivated the Variability of the American Monsoon Systems (VAMOS) Ocean-CloudAtmosphere-Land Study Regional Experiment (VOCALS-REx; hypotheses H1b and H1d; Wood et al. 2011a, their Table 1). While results from VOCALS did shed some light on the characteristics of POCs, significant questions remain. The dominant question was stated in the Mechoso et al. (2014) VOCALS overview paper: "The frequency and climatic importance of POCs remains poorly characterized" (p. 370). In other words, the importance of POCs relative to other sources of $\mathrm{CF}$ variability has not yet been thoroughly examined.

By curious coincidence, many of the observed POC cases in the literature occur near dawn (Table 1). This makes it difficult to separate the proposed roles of aerosols and precipitation from the host of thermodynamic and radiative processes modified by SW fluxes after the sun rises. Wood et al. (2008) found that 12 of the 23 POCs they identified formed either between 0300 and 0600 local time (LT) or between 0600 and 0900 LT. The limited temporal resolution $(3 \mathrm{~h})$ of their data makes it difficult to determine the exact time of formation relative to sunrise. Many of the possible nocturnal POC cases we found in the literature also have data 

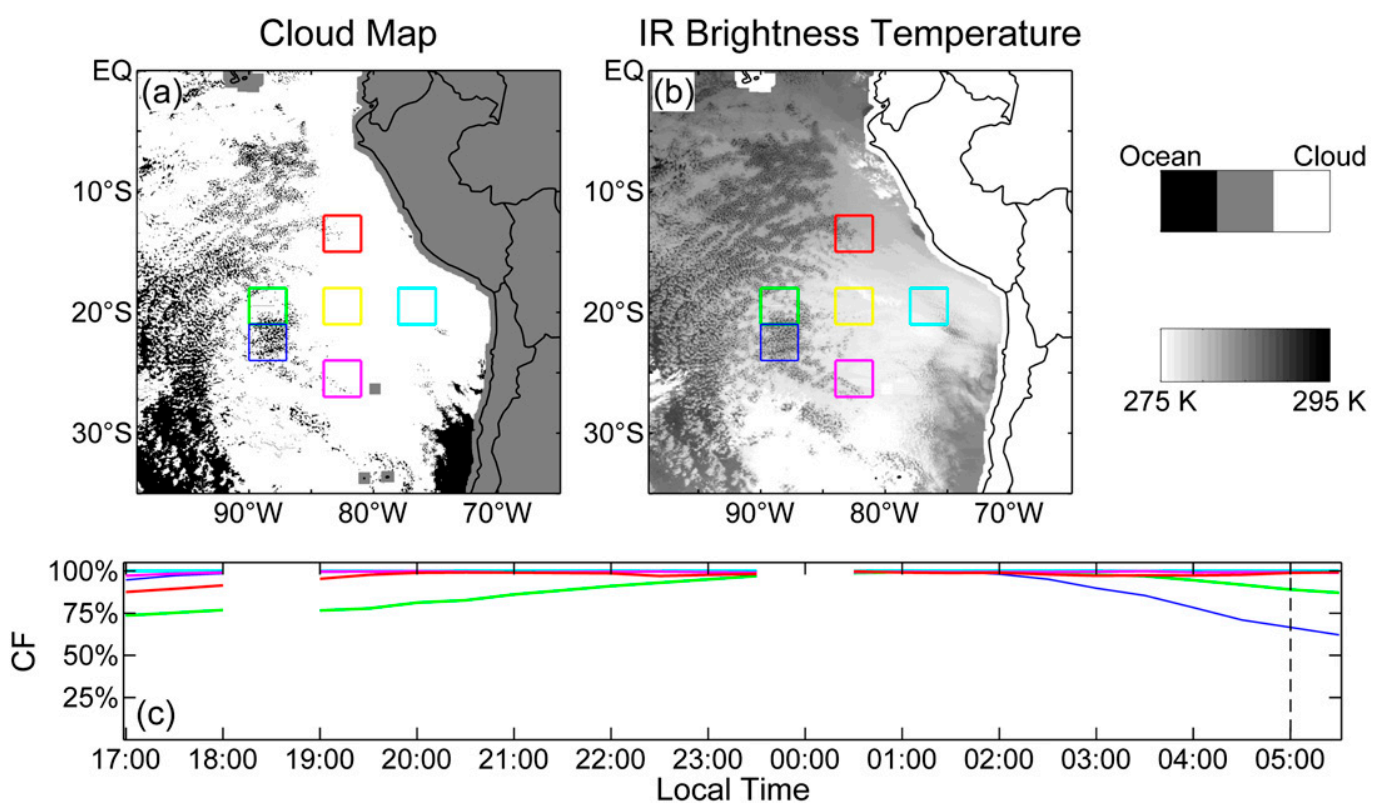

FIG. 1. Overnight changes in CF in six $3^{\circ} \times 3^{\circ}$ boxes in the SE Pacific on 22-23 Aug 2003. A POC formed in the blue box centered at $22.5^{\circ} \mathrm{S}, 88.5^{\circ} \mathrm{W}$ and resulted in a large decrease in CF before dawn. (top) A snapshot of (a) the cloud mask and (b) IR brightness temperature at 0500 LT [shown as a vertical line in (c)]. (c) The time series of CF within each of the color-coded boxes. The gaps in CF at 1830 and 0000 LT are due to missing satellite data. (A loop of the full set of 30-min satellite images associated with the time series is available as supplemental material at the Journals Online website: http://dx.doi.org/10.1175/JCLI-D-14-00648.s1.)

issues that preclude definitive identification of when the POC formed. For example, the 16 November 2001 case from Wood et al. (2008, their Figs. 6 and 7) has missing Geostationary Operational Environmental Satellite (GOES) data for the key overnight period and infers POC formation based only on ceilometer data, a limited ( $\sim 150 \mathrm{~m}$ wide) spatial sample directly over the ship that is insufficient to address the mesoscale organization of the cloud. In the 27 October 2008 case from Wood et al. (2011b, their Fig. 2), high cloud was partly obscuring the region where the aircraft sampled before dawn, which makes it somewhat ambiguous whether the POC was growing in size overnight.

Visual examinations of satellite loops (two examples of which are given in Figs. 1 and 2) show that there are three primary ways that subtropical marine stratocumulus clouds in a given location can change their $\mathrm{CF}$ overnight: 1) advection of the edge of the cloud deck over the region; 2) breakup or reformation of clouds along the edge of the cloud deck; and 3) formation, advection, or filling in of POCs. In this paper, we use the "strict" definition of POC as it was initially given by Stevens et al. (2005): a region of open cells completely surrounded by closed cells. We use the more generic term "broken cloud" to denote an area with CF less than $100 \%$ without the requirement that it be completely surrounded by the larger cloud deck or be organized on the mesoscale. We use the term "cloud breakup" to refer to any decrease in CF. These more broad definitions of broken cloud and cloud breakup can be associated with advection of cloud deck edges, breakup or reformation along cloud deck edges, or POCs.

A complicating factor in the analysis of subtropical marine stratocumulus cloud transitions and the formation of POCs has been the difficulty in developing an automated "POC detector" for use with satellite datasets, which would distinguish among advection, transitions of cloud deck edges, and POCs. No one has yet achieved this. Several methods have been tried (e.g., Wood and Hartmann 2006; Comstock et al. 2007; Muhlbauer et al. 2014). In practice, these methods identify closed- and open-cellular regions by spatial patterns of cloudiness or CF per area. Our statistical analysis in this paper does not distinguish among advection of cloud deck edges, breakup or reformation along cloud deck edges, or POCs because such a determination would currently require the visual examination of thousands of samples of data.

Subtropical marine stratocumulus clouds have a pronounced diurnal cycle with cloud breakup during the day and reformation at night (e.g., Turton and Nicholls 1987; Bretherton et al. 2004; de Szoeke et al. 2012; Burleyson and Yuter 2015). The physical mechanisms behind this diurnal cycle are well understood 

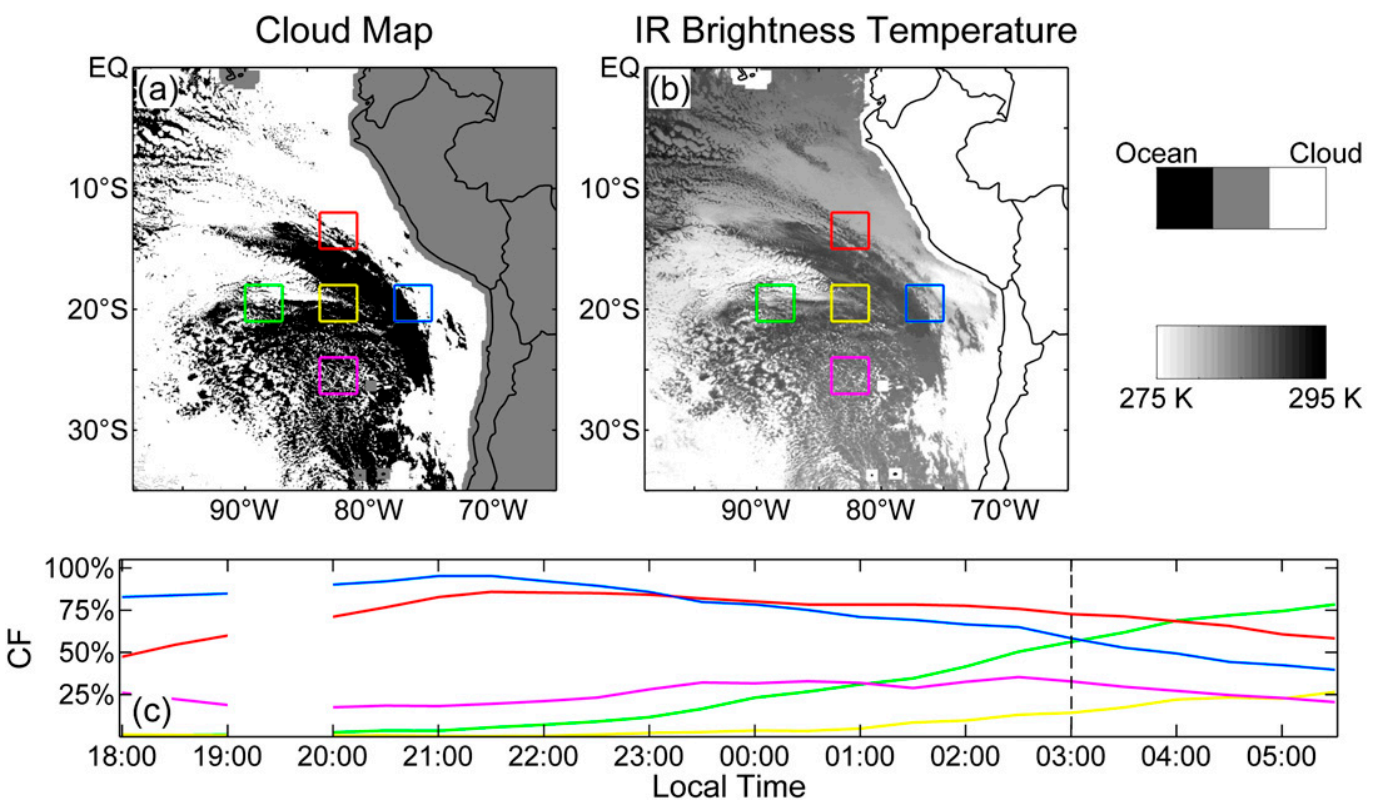

FIG. 2. Overnight changes in CF in five $3^{\circ} \times 3^{\circ}$ boxes in the SE Pacific on 25-26 Jul 2004. An eastward-propagating frontal boundary moved through the domain and resulted in a large decrease in CF overnight within the blue box centered at $19.5^{\circ} \mathrm{S}, 77.5^{\circ} \mathrm{W}$. (top) A snapshot of (a) the cloud mask and (b) IR brightness temperature at $0300 \mathrm{LT}$ [shown as a vertical line in (c)]. (c) The time series of CF within each of the color-coded boxes. The gap in CF at 1930 LT is due to missing satellite data. (A loop of the full set of 30-min satellite images associated with the time series is available as supplemental material at the Journals Online website: http://dx.doi.org/10.1175/JCLI-D-14-00648.s2.)

(James 1959; Lilly 1968; Nicholls 1984), yet many regional and global climate models fail to capture the phase or amplitude of the diurnal cycle in CF (Wyant et al. 2010, their Fig. 11). POCs have generated interest within the community at least partly because they represent a mechanism to break up the cloud deck that can be out of phase with the basic radiatively forced diurnal cycle (Wood et al. 2008). As Mechoso et al. (2014) stated, it remains unclear how much POC-induced cloudiness transitions matter compared to the well-known diurnal cycle. Case studies of individual POCs cannot answer this question. To assess the relative importance of POCs compared to the diurnal cycle of CF driven by SW fluxes, we need to be able to observe cloudiness transitions at relatively high frequencies during both day and night. Previous work on subtropical marine stratocumulus CF based on satellite data has focused on products based in part on visible channels (e.g., Koren and Feingold 2013), 3-hourly infrared (IR) International Satellite Cloud Climatology Project (ISCCP; Rossow and Schiffer 1991) data (e.g., Ghate et al. 2009), four-times-daily Moderate Resolution Imaging Spectroradiometer (MODIS; Platnick et al. 2003) data (e.g., Wood et al. 2008), or twice-a-day CloudSat and Cloud-Aerosol Lidar and Infrared Pathfinder Satellite Observations (CALIPSO; Stephens et al. 2002) datasets (e.g., Leon et al. 2008). These datasets are unable to resolve cloudiness transitions occurring on time scales of a few hours during both day and night. The lack of a viable dataset to observe POC formation events overnight contributes to the large uncertainty in the frequency and causes of POC formation events in the literature (Terai et al. 2014).

A satellite-based analysis also facilitates comparison among the diurnal characteristics of the three main subtropical marine stratocumulus regions. To what degree observed characteristics in one region are similar to those in other regions has implications both for representativeness of past and future field campaign datasets and for numerical model parameterizations. An obvious difference between stratocumulus in the northeast (NE) Pacific and those in the SE Pacific and SE Atlantic is the latitude at which they form (Klein and Hartmann 1993; Wood and Hartmann 2006; Wood 2012). The higher latitude of the stratocumulus cloud deck in the NE Pacific $\left[\sim\left(15^{\circ}-25^{\circ} \mathrm{N}\right)\right]$ puts more area within the cloud deck closer to the extratropical cyclone storm track as compared to the latitude spans for the SE Atlantic $\left[\sim\left(10^{\circ}-\right.\right.$ $\left.\left.20^{\circ} \mathrm{S}\right)\right]$ and SE Pacific $\left[\sim\left(10^{\circ}-25^{\circ} \mathrm{S}\right)\right]$. Furthermore, the NE Pacific cloud deck spends larger portions of the year close to the intertropical convergence zone (ITCZ), which is near $8^{\circ} \mathrm{N}$ from April to November (Xie and Arkin 1998). Previous work has shown that synoptic variability in the subtropics can lead to variations in air masses and stability (George and Wood 2010), boundary 
TABLE 2. A summary of the data sources used in this analysis. All data used are from 2003 to 2010 with the exception of the ship C-band radar-estimated areal-average rain rates, which were only available during the VOCALS-REx field campaign that took place in October and November 2008.

\begin{tabular}{|c|c|c|c|c|}
\hline Variable (Proxy) & Input data & Spatial resolution & Spatial coverage & Temporal resolution \\
\hline Cloud fraction & $\begin{array}{l}\text { Infrared brightness } \\
\text { temperature }\end{array}$ & $4 \mathrm{~km} \times 4 \mathrm{~km}$ & $\begin{array}{l}35^{\circ} \times 35^{\circ} \text { areas } \\
\text { shown in Fig. } 3\end{array}$ & $30 \mathrm{~min}$ \\
\hline Stability (estimated inversion strength) & ECMWF reanalysis & $0.7^{\circ} \times 0.7^{\circ}$ & Global & $\begin{array}{l}4 \text { times daily: } 0000,0600 \text {, } \\
\text { 1200, and } 1800 \text { UTC }\end{array}$ \\
\hline Precipitation area (heavy drizzle area) & $\begin{array}{l}\text { AMSR-E } 89-\mathrm{GHz} \\
\text { passive microwave }\end{array}$ & $6 \mathrm{~km} \times 4 \mathrm{~km}$ & Global & $\begin{array}{l}2 \text { times daily: } \sim 0130 \text { and } \\
1330 \text { LT }\end{array}$ \\
\hline $\begin{array}{l}\text { Precipitation intensity (areal-average } \\
\text { rain rate) }\end{array}$ & $\begin{array}{l}\text { C-band radar during } \\
\text { VOCALS-REx }\end{array}$ & $250 \mathrm{~m} \times 250 \mathrm{~m}$ & $\begin{array}{l}60-\mathrm{km} \text { radius around } \\
\text { the ship }\end{array}$ & $3 \mathrm{~min}$ \\
\hline
\end{tabular}

layer depth (Toniazzo et al. 2011), and the formation of POCs (Allen et al. 2013). The interaction can take the form of cold air advection, fronts crossing through the region, or mesoscale disturbances such as gravity waves generated by synoptic systems.

We use a long-term (2003-2010) IR satellite dataset of 30-min resolution cloud masks (Burleyson and Yuter 2015) to generate approximately 50000 time series of overnight and daytime cloudiness changes in each of the three subtropical marine stratocumulus regions in the NE Pacific, SE Pacific, and SE Atlantic. For portions of the IR dataset period, information on precipitation is available from a ship-based precipitation radar (Burleyson et al. 2013) and an Advanced Microwave Scanning Radiometer for EOS (AMSR-E) drizzle detection product (Miller and Yuter 2013). We focus on three key questions about sub12-hourly cloudiness transitions within the subtropical marine stratocumulus regions:

- What is the relative frequency and area of nocturnal cloud breakup compared to daytime cloud breakup?

- Is there a clear relationship between precipitation and cloud breakup overnight?

- To what degree do the diurnal characteristics of the three subtropical marine stratocumulus regions resemble each other?

Our results demonstrate that the basic radiatively forced diurnal cycle is a very strong control on cloudiness and that deviations in the form of CF decreases at night or CF increases during the day occur infrequently and impact relatively small areas. We also show that $\mathrm{CF}$ changes overnight are largely insensitive to variations in either precipitation area or intensity. Current GCMs show significant amplitude and timing errors in representing the diurnal cycle of subtropical marine stratocumulus CF (Wyant et al. 2010, their Fig. 11b). The results from our analysis suggest that improving the representation of the basic diurnal cycle in stratocumulus-topped marine boundary layer systems may yield significant gains in simulating the mean $\mathrm{CF}$.

\section{Data}

We examine the joint variability of $\mathrm{CF}$, drizzle, and stability using satellite, reanalysis, and ship-based datasets (Table 2). CF is calculated from a 30-min geosynchronous IR (merged IR) product following the methods outlined in Burleyson and Yuter (2015). The binary cloud masks are available every $30 \mathrm{~min}$ from 2003 to 2010 and have a native spatial resolution of $4 \mathrm{~km} \times 4 \mathrm{~km}$. In this IR-derived cloud mask dataset, cloud is defined as optically thick cloud present on scales greater than or equal to $4 \mathrm{~km} \times 4 \mathrm{~km}$. The IR-based cloud masks compare well with anecdotal examples of visible satellite imagery (Figs. 5 and 7 of Burleyson and Yuter 2015). The IR-based cloud masks compare well with MODIS CF values. We calculated a transfer standard to convert MODIS CF values, which have a spatial resolution of $5 \mathrm{~km} \times 5 \mathrm{~km}$ but are based in part on $250 \mathrm{~m}$ nadir spatial resolution data, to binary cloud or no cloud values, which can be more directly compared to the binary $4 \mathrm{~km} \times 4 \mathrm{~km}$ IR-based cloud masks. We found that $87 \%$ of the MODIS $5 \mathrm{~km} \times 5 \mathrm{~km}$ pixel must be covered with clouds before our IR-based product will identify the associated IR pixel as being cloudy. After applying this transfer standard, derived merged-IR CFs are within $\pm 10 \%$ of the MODIS CF $65 \%$ of the time in the NE Pacific, $80 \%$ of the time in the SE Pacific, and $70 \%$ of the time in the SE Atlantic (Burleyson and Yuter 2015).

The spatial patterns of the annual-mean low CF calculated using this method are shown in Figs. 3a-c. The annual-mean $\mathrm{CF}$ values estimated by our method are within $\pm 5 \%$ of the annual-mean MODIS CF across each domain (Burleyson 2013). High CF regions in the center of the cloud deck break up later in the day and have slower rates of cloudiness decreases during the day compared to the cloud deck edges (Burleyson and Yuter 2015). As a result, the edges of the regional cloud decks have the largest amplitude diurnal cycles (Figs. 3d-f). The spatial variability of diurnal cycle amplitude is muted in the NE Pacific (Fig. 3d) compared to the SE Pacific and SE Atlantic (Figs. 3e,f). 
NE Pacific

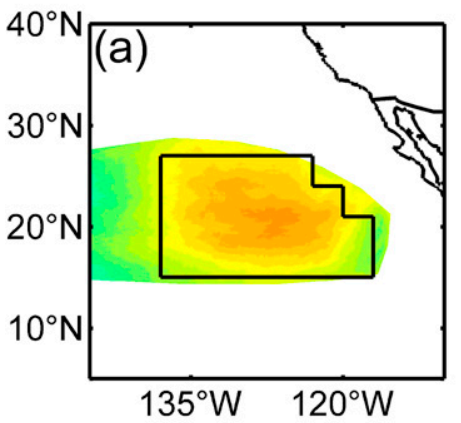

Mar-Apr-May

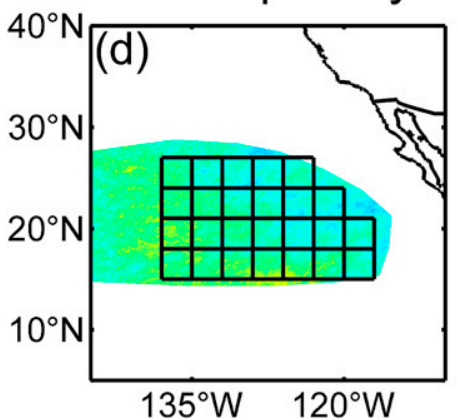

SE Pacific

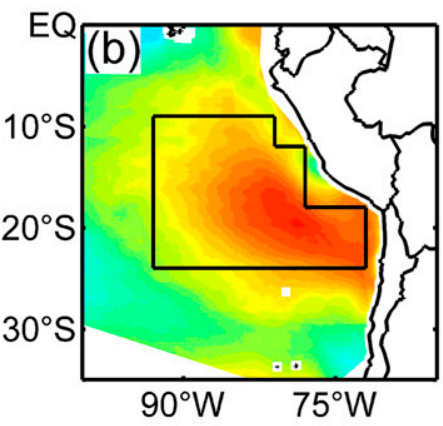

Sep-Oct-Nov

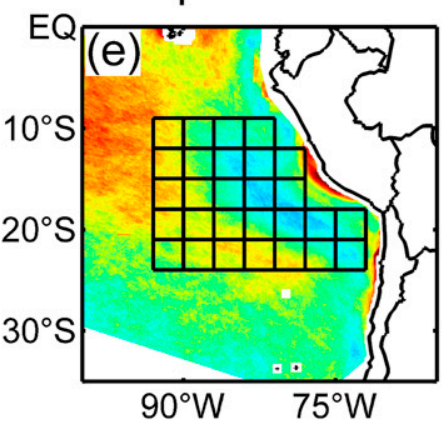

SE Atlantic

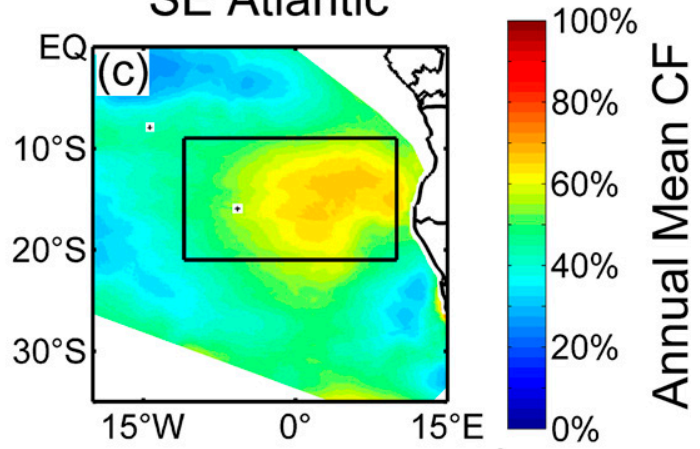

FIG. 3. (top) Annual-mean merged-IR low CF and (bottom) the amplitude of the diurnal cycle during the peak season of $4 \mathrm{~km} \times 4 \mathrm{~km}$ CF in (a),(d) the NE Pacific for March-May, (b),(e) the SE Pacific for September-November, and (c),(f) the SE Atlantic for SeptemberNovember. This figure is adapted from Burleyson and Yuter (2015), where CF is calculated as a frequency from data with $4 \mathrm{~km} \times 4 \mathrm{~km}$ spatial resolution and the peak season is defined as the season in which the majority of pixels within the polygons in (top) have their maximum seasonal-mean merged-IR CF. The amplitude is the difference between the maximum and minimum hourly-mean CF at any time during the day. Black lines in (top) outline the area where regional CF is calculated and in (bottom) delineate the $3^{\circ} \times 3^{\circ}$ boxes where local CF is calculated. Boxes cover regions where ice clouds occur $<35 \%$ of the time and where the input-merged IR satellite data do not have data quality issues (for full details, see Burleyson and Yuter 2015).

We calculate $\mathrm{CF}$ on spatial scales of $3^{\circ} \times 3^{\circ}$ and larger to minimize the impact of horizontal advection on our interpretation of temporal variability. Typical wind speeds at cloud level in the SE Pacific are $\sim 7 \mathrm{~m} \mathrm{~s}^{-1}$, which is equivalent to $\sim 300 \mathrm{~km}$ of advection in $12 \mathrm{~h}$. We examine a set of $3^{\circ} \times 3^{\circ}$ boxes (bottom row of Fig. 3 ) for each of the marine stratocumulus regions in the SE Pacific ( 28 boxes), SE Atlantic ( 28 boxes), and NE Pacific ( 25 boxes). We use the term "regional cloud fraction" to reference the CF calculated over all of the $3^{\circ} \times$ $3^{\circ}$ boxes within a given region (delineated by the polygon outlines in the top row of Fig. 3). The specific study regions are selected based on high annual frequency of low cloud, low $(<35 \%)$ annual frequency of high cirrus clouds that may obscure low clouds in the satellite data, and the absence of satellite data artifacts [for full details see Burleyson and Yuter (2015)].

We use the time series of $\mathrm{CF}$ at spatial resolutions of $3^{\circ} \times 3^{\circ}$ to examine net cloudiness changes over 12 -h periods from dusk to dawn and from dawn to dusk as well changes over a few hours overnight (e.g., Figs. 1 and 2).
Throughout the text, we use the abbreviation CF to indicate cloud fraction at a particular time and $\Delta \mathrm{CF}$ to indicate the difference between cloud fractions at different times. For example, if for a particular box $\mathrm{CF}$ at $0600 \mathrm{LT}$ is $30 \%$ and $\mathrm{CF}$ at $1800 \mathrm{LT}$ is $70 \%$, then $\Delta \mathrm{CF}=$ $+40 \%$. In some parts of our analysis, it is useful to distinguish between small and large $\mathrm{CF}$ changes overnight and during the day. We use the following terminology to describe CF changes: $\mathrm{A}$ large decrease is $\Delta \mathrm{CF}<-15 \%$, a small decrease is $-15 \%<\Delta \mathrm{CF}<-2 \%$, a neutral change is $-2 \%<\Delta \mathrm{CF}<+2 \%$, a small increase is $+2 \%<$ $\Delta \mathrm{CF}<+15 \%$, and a large increase is $\Delta \mathrm{CF}>+15 \%$. In this study, $\mathrm{CF}$ at dawn is the average value from 0500 to $0600 \mathrm{LT}$ and CF at dusk is the average value from 1700 to $1800 \mathrm{LT}$. These statistics are used to record the CF just before the sun rises and just before the sun sets each day. Local time is calculated as a function of longitude in the center of each $3^{\circ} \times 3^{\circ}$ box.

In Fig. 1, a POC forms overnight within the area outlined by the blue box centered at $22.5^{\circ} \mathrm{S}, 88.5^{\circ} \mathrm{W}$. This formation event resulted in a large decrease in 
$\mathrm{CF}(\Delta \mathrm{CF}<-40 \%)$ from a maximum value of $100 \%$ at $0100 \mathrm{LT}$ to $60 \%$ at $0600 \mathrm{LT}$. The green box just to the north of the blue box also shows increasing CF until about $0400 \mathrm{LT}$, after which CF decreases to near $80 \%$ by 0600 LT. In Fig. 2, an eastward-propagating frontal boundary advects through the region overnight, which leads to a gradual but significant decrease in $\mathrm{CF}(\triangle \mathrm{CF}<$ $-30 \%)$ within the blue and red boxes. The pink box centered at $25.5^{\circ} \mathrm{S}, 82.5^{\circ} \mathrm{W}$ and remains in a broken cloud region throughout the night. The green box centered at $19.5^{\circ} \mathrm{S}, 88.5^{\circ} \mathrm{W}$ and shows increasing $\mathrm{CF}$ overnight. Similar time series were calculated for $8 \mathrm{yr}$ of overnight and daytime periods yielding over 50000 samples of daytime and overnight changes in CF for each of the three subtropical marine stratocumulus regions. In addition to the two examples given in the supplemental material of this paper, there are several examples of the IR-derived cloud masks compared to GOES visible imagery in the suplemental material of Burleyson and Yuter (2015; copies of the supplemental material are available online at ftp://precip.meas.ncsu. edu/pub/casey/Methods_Paper_Electronic_Supplement/).

We use estimated inversion strength (EIS; Wood and Bretherton 2006) as a proxy for the strength of the subsidence inversion in each region. EIS is calculated using ERA-Interim data (ECMWF 2009). Reanalysis data are available every $6 \mathrm{~h}$ at a spatial resolution of $0.7^{\circ} \times 0.7^{\circ}$. Repeating the analysis using lower tropospheric stability (Klein and Hartmann 1993) gives similar results.

Drizzle is identified using the empirical detection technique of Miller and Yuter (2013), which is based on AMSR-E 89-GHz passive microwave measurements. The AMSR-E swath width $(1445 \mathrm{~km})$ is roughly 1000 times wider than the CloudSat radar swath $(1.4 \mathrm{~km})$ and thus provides a larger sample domain to detect drizzling stratocumulus clouds. After screening out clouds containing ice, heavy drizzle is detected by comparing local maxima in emission energy against a cloudfree background temperature. This method yields a binary mask within the AMSR-E swath that identifies the occurrence of heavy drizzle, roughly equivalent to liquid water path (LWP) larger than $\sim 200 \mathrm{~g} \mathrm{~m}^{-2}$ within each $6 \mathrm{~km} \times 4 \mathrm{~km}$ pixel. Miller and Yuter's method works during both day and night. In comparison, MODIS LWP, which has a 1-km spatial resolution, works only during the day (Platnick et al. 2003). AMSR-E LWP, which is available both day and night but with a native spatial resolution of $10 \mathrm{~km} \times 14 \mathrm{~km}$, is too coarse to detect many heavily drizzling cells (Wentz and Meissner 2000).

For the SE Pacific, we also use a 31-day time series of radar-derived areal-average rain rate collected aboard the National Oceanic and Atmospheric Administration (NOAA) Research Vessel (R/V) Ronald H. Brown during VOCALS-REx in October and November 2008. A C-band radar aboard the ship measured precipitation frequency and intensity [see Wood et al. (2011a) and Burleyson et al. (2013) for more details on the radar sampling and measurements]. To provide collocated $\mathrm{CF}$ values along the ship track, we calculate $\mathrm{CF}$ over a $1^{\circ} \times 1^{\circ}$ box centered on the ship for the portions of the cruises south of $15^{\circ} \mathrm{S}$. The $1^{\circ} \times 1^{\circ}$ box roughly corresponds to the $120-\mathrm{km}$-diameter area scanned by the radar.

\section{Temporal changes in cloudiness}

\section{a. Diurnal variability}

Previous work has shown that subtropical marine stratocumulus clouds are very likely to experience decreases in cloudiness during the day and increases in cloudiness overnight (Nicholls 1984; Turton and Nicholls 1987; Betts 1990). The mean diurnal cycles of regional $\mathrm{CF}$ over annual and seasonal periods for each region are shown in Fig. 4. Consistent with previous work (Turton and Nicholls 1987; Klein et al. 1995; Rozendaal et al. 1995), the diurnal minimum in CF occurs between 1400 and $1500 \mathrm{LT}$, when daytimeaverage CFs are greater than $\sim 50 \%$, and slightly later in the day, when CF is lower (e.g., the SE Pacific during December-February). For lower CF seasons, the filling in of broken cloud as SW fluxes decrease occurs later in the afternoon than for higher $\mathrm{CF}$ seasons.

There are several types of differences in the diurnal cycles among the three regions, which suggest different superpositions of factors controlling regional CF. The NE Pacific has the smallest seasonal variability, and the SE Atlantic has the largest. The largest amplitude diurnal cycle $(\triangle \mathrm{CF}=37 \%)$ occurs in the SE Pacific during December-February. The highest CF in any region or season occurs overnight in the SE Pacific during SeptemberNovember, where the mean early morning CF is greater than $90 \%$.

\section{b. Net 12-h changes}

We can examine the frequency of different changes in cloudiness over the $12 \mathrm{~h}$ during the day by comparing $\mathrm{CF}$ in a given $3^{\circ} \times 3^{\circ}$ box at dusk against the $\mathrm{CF}$ in that box at the previous dawn (Fig. 5). Similarly, the changes in $\mathrm{CF}$ in the $12 \mathrm{~h}$ overnight can be seen by examining $\mathrm{CF}$ at dawn as a function of $\mathrm{CF}$ at the previous dusk (Fig. 6). $\mathrm{CF}$ is calculated in each of the $3^{\circ} \times 3^{\circ}$ boxes shown in Fig. 3, and the frequencies shown are for all boxes in a given region combined. 
(a)

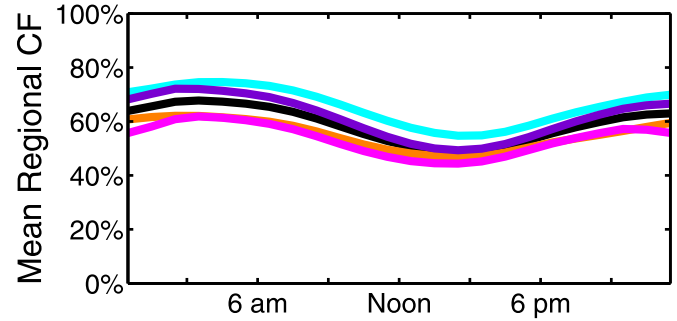

(b)

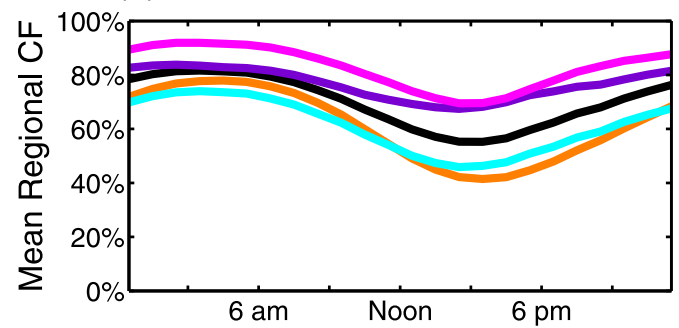

\section{Mean Diurnal Cycle}

All Data

Dec-Jan-Feb

Mar-Apr-May

-Jun-Jul-Aug

Sep-Oct-Nov

FIG. 4. Diurnal cycle of the mean regional CF for all data (black lines), December-February (orange lines), MarchMay (cyan lines), June-August (purple lines), and September-November (pink lines) in the (a) NE Pacific, (b) SE Pacific, and (c) SE Atlantic. The CF and local time are found in each of the $3^{\circ} \times 3^{\circ}$ boxes, and the regional $\mathrm{CF}$ is found by combining the cloudy areas over the polygons outlined in the top panels of Fig. 3. Data are smoothed using a 3-h running-mean filter to remove artifacts associated with intermittent gaps in the 30-min IR dataset.

During the day, $\mathrm{CF}$ on $3^{\circ} \times 3^{\circ}$ scales usually either decreases from its value near dawn or maintains a low value (Fig. 5). For CFs at dawn greater than $50 \%$, the mean $\Delta \mathrm{CF}$ can be as large as $-35 \%$ in every region.
For CFs at dawn greater than $90 \%$, the mode of the CF distribution at dusk is also greater than $90 \%$, indicating that overcast cloud decks are somewhat resistant to breaking up during the day. Strong signals (a)

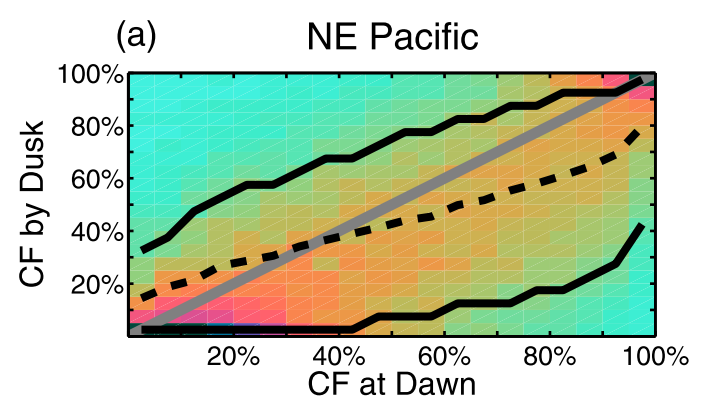

(b)

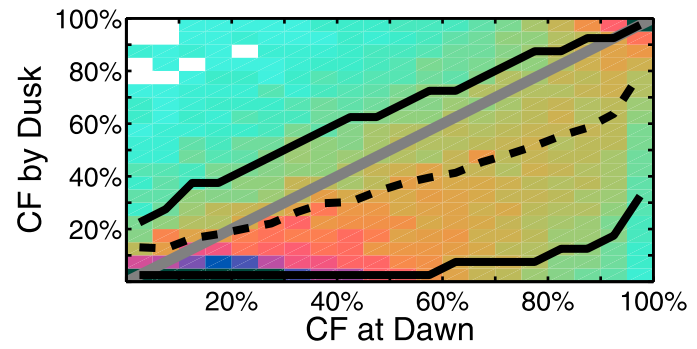

(c)

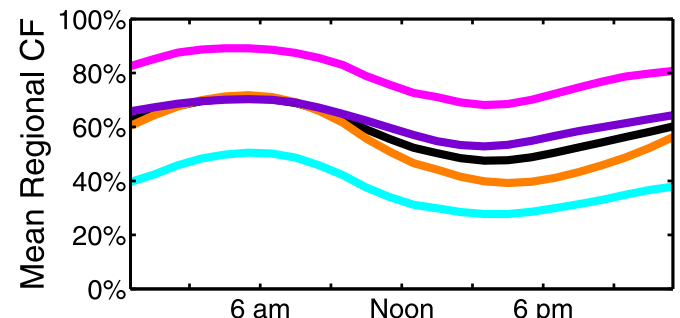

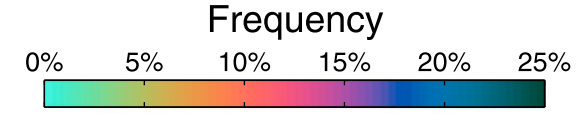

(c)

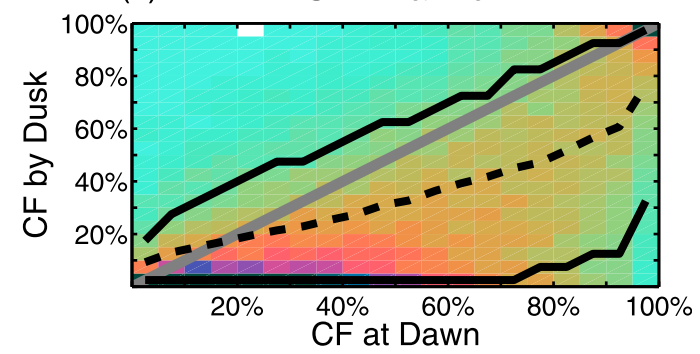

FIG. 5. Data density diagrams showing the joint distribution of CF by dusk ( $y$ axis) conditioned on the CF at dawn ( $x$ axis) in the (a) NE Pacific, (b) SE Pacific, and (c) SE Atlantic. Darker colors indicate more frequent occurrences. In each panel, the solid lines show the 10th and 90th percentiles of the CF distribution, whereas the dotted line indicates the mean. The $\mathrm{CF}$ is calculated in the $3^{\circ} \times 3^{\circ}$ boxes shown in the bottom panel of Fig. 3 , and the probabilities shown are in all boxes combined for a given region. The gray line transecting the figure diagonally is the 1:1 line. 
(a)

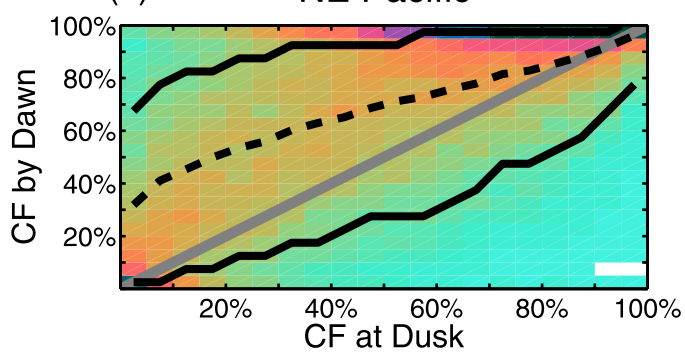

(b)

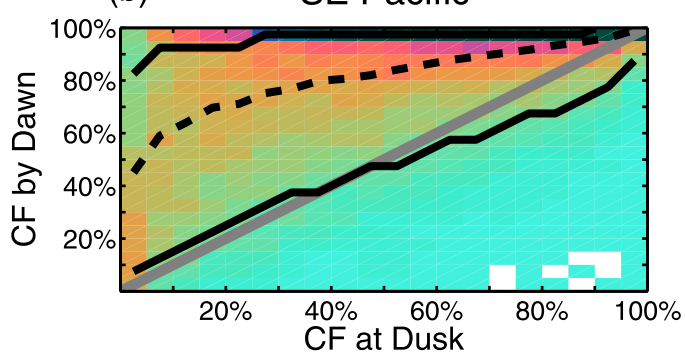

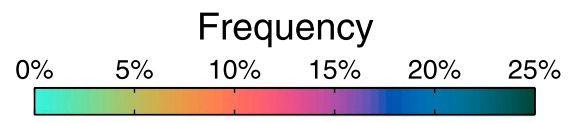

(c)

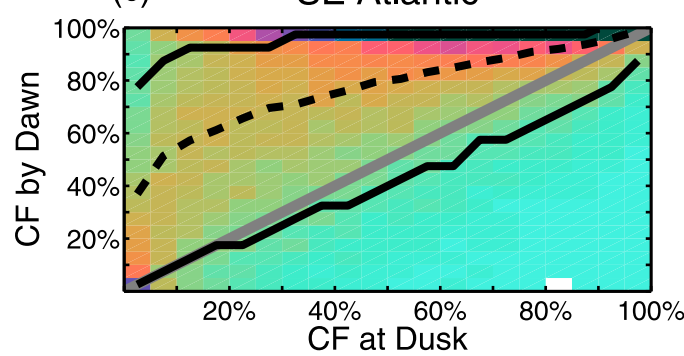

FIG. 6. As in Fig. 5, but for $\mathrm{CF}$ at dawn distributions conditioned on $\mathrm{CF}$ at dusk.

of increasing $\mathrm{CF}$ overnight on $3^{\circ} \times 3^{\circ}$ spatial scales can be seen in Fig. 6. The mean $\mathrm{CF}$ at dawn is always greater than or equal to the starting $\mathrm{CF}$ at dusk. Net overnight changes in $\mathrm{CF}$ on $3^{\circ} \times 3^{\circ}$ scales are either positive or neutral more than $77 \%$ of the time in the NE Pacific and more than $88 \%$ of the time in the SE Pacific and SE Atlantic (not shown). The largest increases in $\mathrm{CF}$ overnight are associated with lower starting $\mathrm{CFs}$, which can increase by as much as $50 \%$ overnight. The modes of the distributions show that the cloud deck often fully reforms overnight (CF goes to $100 \%$ by dawn), when $\mathrm{CF}$ at dusk is greater than $30 \%$. There is a low frequency of decreases in $\mathrm{CF}$ overnight in all three regions (plot area below the 1:1 diagonal line in Fig. 6). Large overnight decreases in $\mathrm{CF}(\Delta \mathrm{CF}<-15 \%)$ on $3^{\circ} \times 3^{\circ}$ scales occur less than $5 \%$ of the time in the SE Pacific and SE Atlantic and approximately $11 \%$ of the time in the NE Pacific.

\section{c. Frequency of cloud breakup overnight}

The net change in $\mathrm{CF}$ in the $12 \mathrm{~h}$ from dusk to dawn (Fig. 6) does not address the full set of scenarios in which nocturnal cloud breakup could occur. CF changes may not be monotonic over $12 \mathrm{~h}$, and it is possible for an area to have both an increase and decrease in $\mathrm{CF}$ at different times overnight. An example would be if the cloud deck in a given location reforms after dusk and then either a front moves through or a nocturnal POC forms or advects over in the hours just before dawn. To account for this possible scenario, we focus on the subset of time series within $3^{\circ} \times 3^{\circ}$ boxes where $\mathrm{CF}$ is $\geq 90 \%$ at any time during the night, a sample size between 24000 and 26000 cases in each of the three regions (Fig. 7). When $\mathrm{CF}$ is $\geq 90 \%$ sometime overnight, the probability of $\mathrm{CF} \geq 90 \%$ at dawn is $73.1 \%$ in the NE Pacific, $80.9 \%$ in the SE Pacific, and $83.8 \%$ in the SE Atlantic. When CF is $\geq 90 \%$ sometime overnight, the probability of $\mathrm{CF}<75 \%$ at dawn is $9.2 \%$ in the NE Pacific and approximately $5 \%$ in the SE Pacific and SE Atlantic. In the NE Pacific, only $3.3 \%$ of time series with $\mathrm{CF} \geq 90 \%$ sometime overnight have $\mathrm{CF}<60 \%$ at dawn, and the frequencies are $1.5 \%$ in the SE Pacific and $1.6 \%$ in the SE Atlantic. The category with $\mathrm{CF} \geq 90 \%$ sometime overnight and $\mathrm{CF}<60 \%$ at dawn is closest to the characteristics associated with the nocturnal formation of a POC (Wood et al. 2008; Berner et al. 2013). A frequency of $1.5 \%$ in the SE Pacific corresponds to one cloud breakup event occurring somewhere within the domain, on average, every third night. This value for the SE Pacific is in good agreement with the results of Wood et al. (2008), who found on average 1 POC formation event every 2.7 days in the SE Pacific during September and October 2001. For the conditional subset of cases where $\mathrm{CF}<$ $60 \%$ at dawn, the $1.5 \%, 1.6 \%$, and $3.3 \%$ values for the SE Pacific, SE Atlantic, and NE Pacific, respectively, include some POC formation events (e.g., Fig. 1) but also include events with cloudiness transitions that are not related to POCs (e.g., Fig. 2) and thus likely overestimate the actual frequency of nocturnal POC formation events. 
(a)

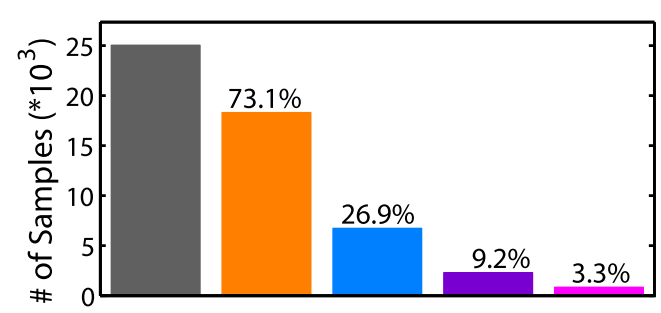

(b)

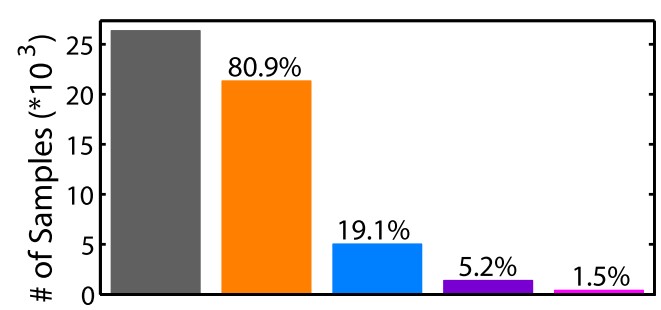

\section{Overnight CF Time Series}

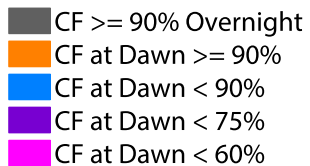

FIG. 7. Relative proportions of the time $\mathrm{CF}$ in a $3^{\circ} \times 3^{\circ}$ box reaches $\geq 90 \%$ overnight and then decreases by various amounts by dawn for the (a) NE Pacific, (b) SE Pacific, and (c) SE Atlantic. The gray bars represent the number (in thousands) of time series where $\mathrm{CF}$ is $\geq 90 \%$ in at least one 30 -min sample from the overnight time series. Bars to the right of the gray bar are conditional on $\mathrm{CF}$ reaching $\geq 90 \%$ at some time overnight and represent different CFs at dawn: $\mathrm{CF}$ is $\geq 90 \%$ (orange bars), $<90 \%$ (blue bars), $<75 \%$ (purple bars), and $<60 \%$ (pink bars). The number on top of each bar indicates the relative frequency compared to all samples in which CF is $\geq 90 \%$ at any time overnight.

\section{d. Relative amounts of regional cloud breakup during the day versus at night}

From a radiative balance standpoint, the change in the area of low clouds is a relevant quantity. We can put into context the spatial scale of the infrequent overnight decreases in CF relative to the typical daytime decreases in $\mathrm{CF}$ driven by $\mathrm{SW}$ radiation. For each region, we combine the 30-min CF time series for the set of $3^{\circ} \times 3^{\circ}$ boxes to create a 30-min regional $\mathrm{CF}$ time series and then convert the percentage $\mathrm{CF}$ into an area $\left(\mathrm{km}^{2}\right)$ of low cloud cover. We determine the difference in regional cloud area for the $12 \mathrm{~h}$ overnight and the $12 \mathrm{~h}$ during the day. These values, both positive and negative, are sorted by size and plotted as cumulative distributions for day and night in Fig. 8.

The SE Pacific and SE Atlantic have similar distributions of daytime and overnight cloud area changes (Fig. 8). The regional area examined for the NE Pacific is slightly smaller than that for the SE Pacific and SE Atlantic (Fig. 3). The shape of the cumulative distribution is steeper (underlying distribution is narrower) in the NE Pacific even when the net regional area changes are normalized (not shown). In the SE Pacific and SE Atlantic, a typical decrease in cloud area (median $\leq-5.7 \times$ $10^{5} \mathrm{~km}^{2}$ ) during the day is equivalent to $25 \%$ or more of the annual-mean cloud deck area. The median changes in cloud area during the day (about $-3.5 \times 10^{5} \mathrm{~km}^{2}$ in the NE Pacific, $-5.7 \times 10^{5} \mathrm{~km}^{2}$ in the SE Pacific, and $-6.3 \times 10^{5} \mathrm{~km}^{2}$ in the SE Atlantic) are slightly larger than the median changes in cloud area overnight (about $+3.4 \times 10^{5} \mathrm{~km}^{2}$ in the NE Pacific, $+5.5 \times 10^{5} \mathrm{~km}^{2}$ in the SE Pacific, and $+6.3 \times 10^{5} \mathrm{~km}^{2}$ in the SE Atlantic). The offset between the median values during the day and overnight for a given region is related to differences in the tails of the distributions. In all three regions, it is more common for cloud area to decrease overnight than for cloud area to increase during the day. The mean values during the day and overnight in each region are balanced and agree to within $0.05 \%$ in the SE Pacific and NE Pacific and to within $0.01 \%$ in the SE Atlantic.

If we define a significant cloud area decrease as at least $-1 \times 10^{5} \mathrm{~km}^{2}$ (approximately the area of one $3^{\circ} \times 3^{\circ}$ box), then a significant overnight decrease occurs less than $3.9 \%$ of the time in the NE Pacific, $0.8 \%$ of the time in the SE Pacific, and $0.7 \%$ of the time in the SE Atlantic. Daytime cloud area decreases of at least $-1 \times$ $10^{5} \mathrm{~km}^{2}$ occur more than $86.0 \%, 88.8 \%$, and $96.2 \%$ of the time in the NE Pacific, SE Pacific, and SE Atlantic, respectively. Significant overnight cloud area decreases include both POC formation events and advection of the 


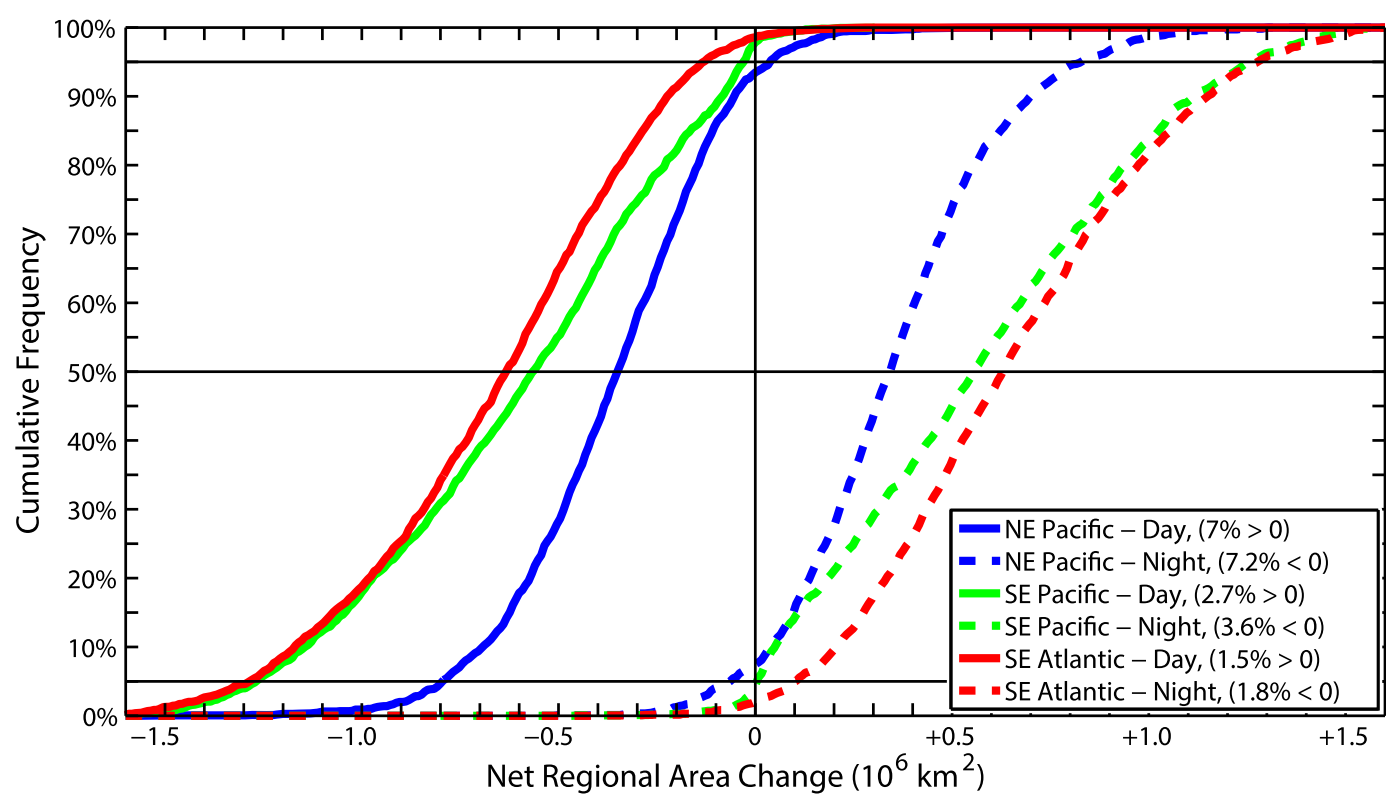

FIG. 8. Cumulative frequency distribution of the net change in area of the cloud deck during the day (solid lines) and overnight (dotted lines) in the NE Pacific (blue lines), SE Pacific (green lines), and SE Atlantic (red lines). The figure legend indicates the frequency of net increases during the day and net decreases overnight in each region. Regional cloud area is calculated in the polygons outlined in the top panels of Fig. 3. The total area over which regional cloud fraction is calculated is approximately $2.3 \times 10^{6} \mathrm{~km}^{2}$ in the NE Pacific, $2.6 \times 10^{6} \mathrm{~km}^{2}$ in the SE Pacific, and $3.0 \times 10^{6} \mathrm{~km}^{2}$ in the SE Atlantic.

overcast cloud deck edge (i.e., Figs. 1 and 2). During the day, partially broken cloud is more likely than overcast cloud to break up further (Burleyson and Yuter 2015, their Fig. 20). Hence, cloud breakup overnight will contribute to cloud breakup during the day. However, the rarity of overnight cloud breakup events and the small areas that are impacted indicates that the overall influence of overnight decreases in $\mathrm{CF}$ on regional radiative budgets is much smaller than typical daytime cloud breakup.

\section{e. Spatial structure}

The spatial variability of the frequency of the cloud deck breaking up overnight could reflect the underlying cause. All three subtropical marine stratocumulus regions have significant spatial variations in precipitation, boundary layer depth, aerosol concentrations, and stability. Most of these vary longitudinally with increasing precipitation and boundary layer depth and decreasing aerosol concentrations and stability farther from the coast (e.g., Wood and Bretherton 2004; Leon et al. 2008; Zuidema et al. 2009; de Szoeke et al. 2012). We show the spatial structure of the frequency of a given change in net cloudiness overnight on $3^{\circ} \times 3^{\circ}$ spatial scales in Fig. 9. There are clear longitudinal variations in the frequency of large increases in CF overnight (far right column of Fig. 9) and of neutral
CF changes (center column of Fig. 9). These variations are oriented roughly parallel to the coast line in the case of the NE Pacific and SE Pacific. Neutral CF changes occur more often where $\mathrm{CF}$ is already high and cannot increase further (cf. center column of Fig. 9 with Fig. 3). Large increases in CF overnight are more likely to occur on the western edge of each of the cloud decks. In the two Southern Hemisphere subtropical marine stratocumulus regions, there is a slightly higher frequency of large increases in CF overnight on the poleward (southern) edge of the cloud deck. The spatial gradients of CF are weaker in the NE Pacific region for which we have data; hence, this signal is not as evident there.

In comparison, within a given region, there are only weak spatial gradients in the frequency of large decreases in CF overnight (far left column of Fig. 9). In the NE Pacific, the frequency of $\Delta \mathrm{CF}<-15 \%$ overnight is slightly larger along the southern edge of the cloud deck (i.e., closer to ITCZ) compared to areas farther north. There is no clear relationship between the welldocumented longitudinal gradients in precipitation and aerosol concentrations and the frequency of cloud breakup overnight. This is consistent with the POC climatology in Wood et al. (2008, their Fig. 10a), which showed that POC formation events appeared to be randomly distributed in space. 


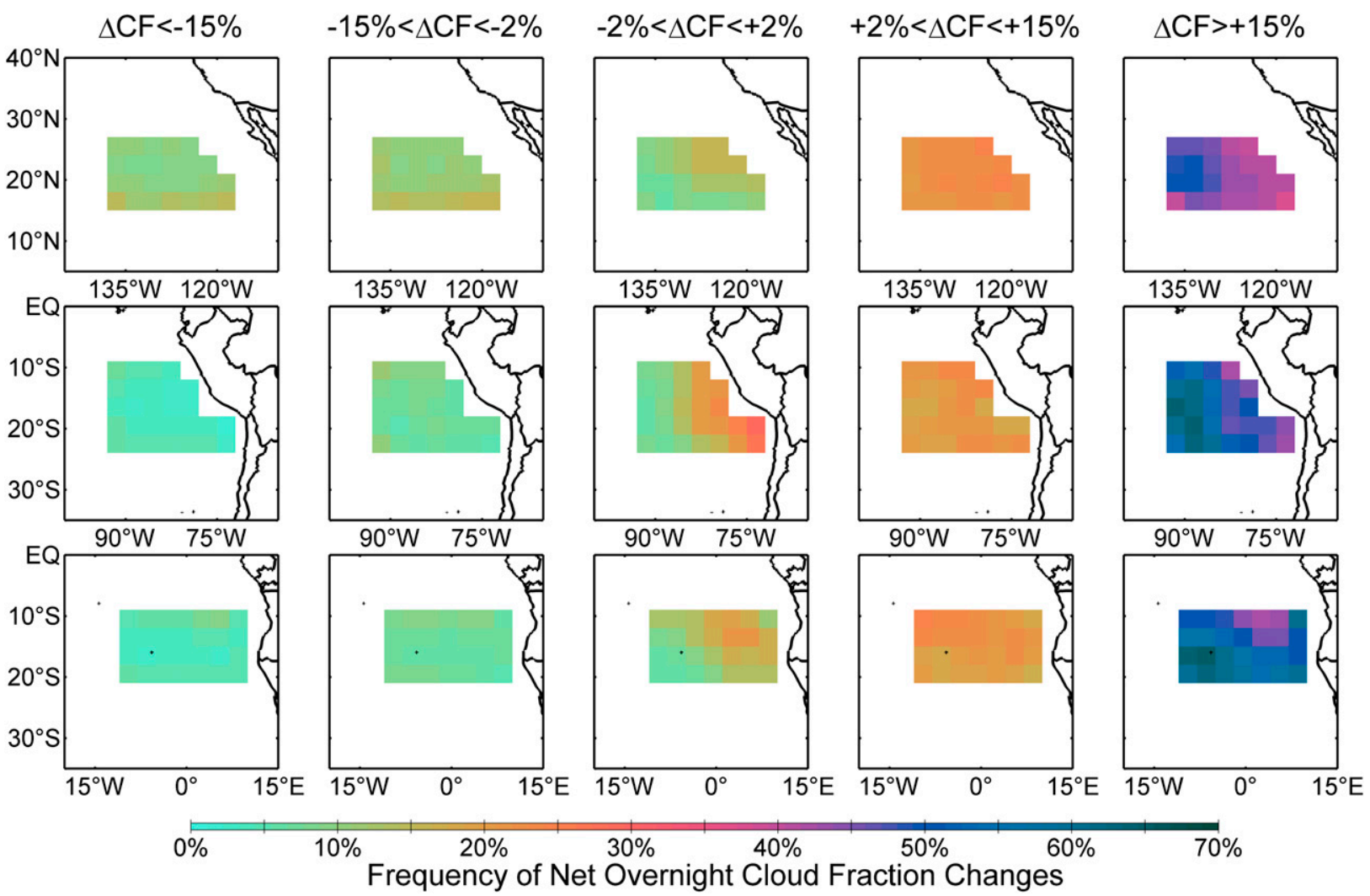

FIG. 9. Spatial patterns of the frequency of overnight $\mathrm{CF}$ changes for $3^{\circ} \times 3^{\circ}$ boxes in each region: (left)-(right) large decreases in $\mathrm{CF}$ $(\Delta \mathrm{CF}<-15)$, small decreases in $\mathrm{CF}(-15 \%<\Delta \mathrm{CF}<-2 \%)$, neutral $\mathrm{CF}$ changes $(-2 \%<\Delta \mathrm{CF}<+2 \%)$, small increases in $\mathrm{CF}(+2 \%<$ $\Delta \mathrm{CF}<+15 \%)$, and large increases in $\mathrm{CF}(\Delta \mathrm{CF}>+15 \%)$. Data are from the (top) NE Pacific, (middle) SE Pacific, and (bottom) SE Atlantic. Darker colors indicate more frequent occurrences. The frequencies are given with respect to all overnight time series such that summing along a given row (region) over all five columns adds up to $100 \%$ in each $3^{\circ} \times 3^{\circ}$ box.

\section{Lack of sensitivity to precipitation}

Previous studies have linked the formation of POCs to precipitation and the subsequent wet scavenging of aerosols (e.g., Stevens et al. 2005; Savic-Jovcic and Stevens 2008; Wang and Feingold 2009). To take advantage of our unique combination of datasets, we perform an additional set of analyses in which we use the AMSR-E $89-\mathrm{GHz}$ precipitation area measurement made during the 0130 LT satellite overpass as an "initial condition" and then track the evolution of CF in each $3^{\circ} \times 3^{\circ}$ box over the subsequent hours to examine the sensitivity of $\mathrm{CF}$ to changes in precipitation area.

In Fig. 10, we show the distribution of CF changes over a period of 1 and $3 \mathrm{~h}$ after the 0130 LT overpass. We limit the time span to focus on periods during full darkness (before 0430 LT) when there are no possible SW influences. The distributions are conditioned on the area fraction of heavy drizzle measured by the satellite. In all of the panels in Fig. 10, the distribution of $\Delta \mathrm{CF}$ after $1 \mathrm{~h}$ and $3 \mathrm{~h}$ is tightly clustered around $0 \%$ and the mode of each distribution is slightly positive. This indicates a lack of sensitivity of $\mathrm{CF}$ to variations in drizzle area on $3^{\circ} \times 3^{\circ}$ spatial scales and time scales of $1-3 \mathrm{~h}$. CF across the span of drizzle areas measured is most likely to be changing either very little or slightly increasing between 0130 and 0430 LT. These statistical characteristics reflect the fact that $\mathrm{CF}$ in a large subset of the $3^{\circ} \times 3^{\circ}$ boxes has already increased to near $100 \%$ by $0130 \mathrm{LT}$, thus limiting the possibility of further positive increases (Burleyson and Yuter 2015). Although the signal is somewhat hampered by smaller sample sizes for the larger drizzle area events, this analysis also suggests that regions with larger drizzle areas are actually more resistant to cloud breakup in the early morning hours. These results are contrary to what would be expected if drizzle were routinely associated with the breakup of clouds overnight.

One limitation of the satellite-based precipitation area sensitivity analysis is that it fails to account for changes in precipitation intensity because the satellite only measures the area of heavy drizzle. POC regions 

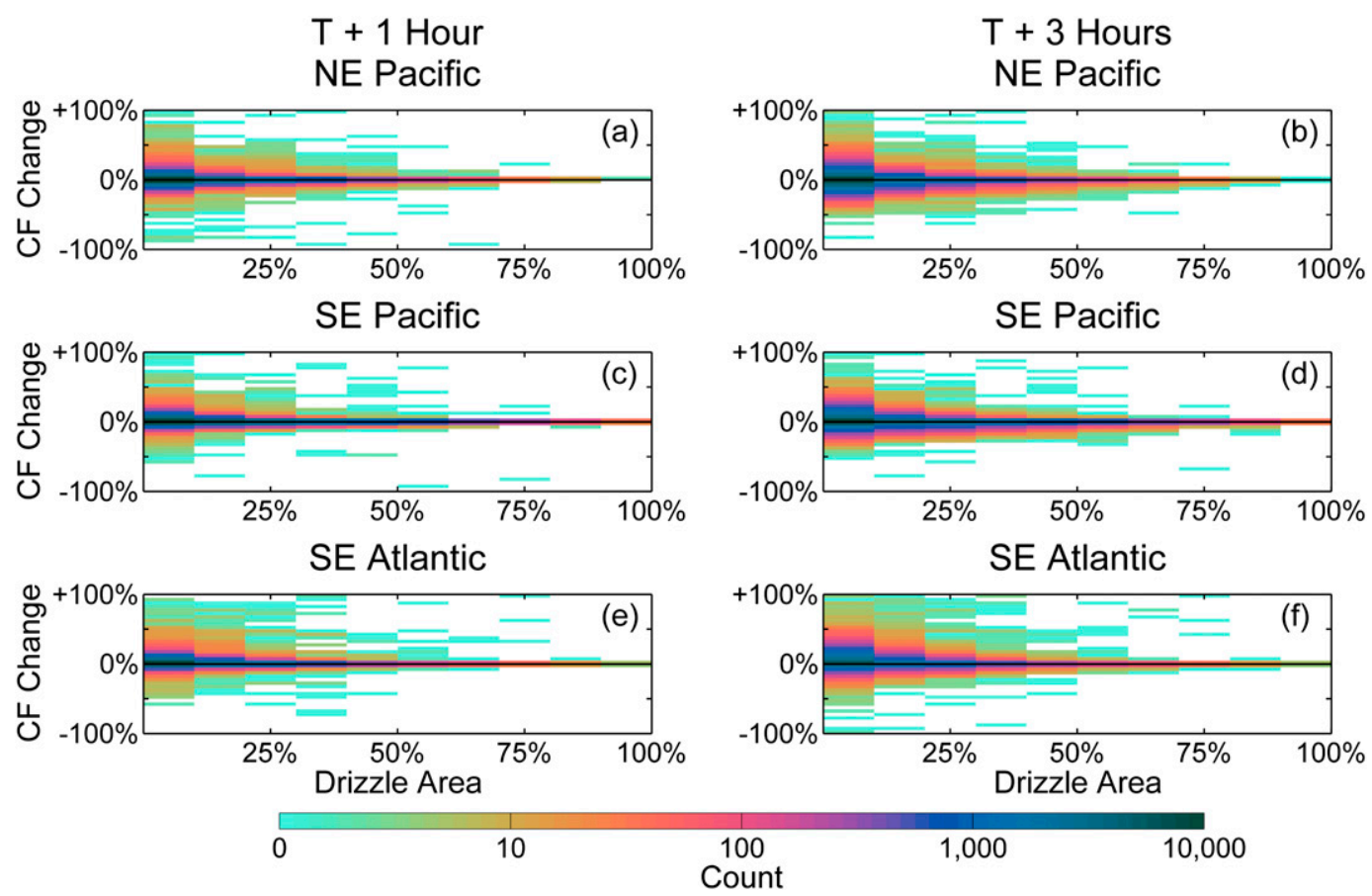

FIG. 10. Data density diagrams showing the joint frequency distributions of the area of heavy drizzle (expressed as the percentage of the $3^{\circ} \times 3^{\circ}$ box covered by drizzle) detected during the 0130 LT AMSR-E overpass and subsequent changes in CF: changes for (a),(c),(e) $+1 \mathrm{~h}(\Delta \mathrm{CF}$ between 0130 and $0230 \mathrm{LT})$ and (b),(d),(f) $+3 \mathrm{~h}(\Delta \mathrm{CF}$ between 0130 and $0430 \mathrm{LT})$. The probabilities shown are for all $3^{\circ} \times 3^{\circ}$ boxes that overlapped with individual AMSR-E orbit swaths for a given region combined. Data are from the (top) NE Pacific, (middle) SE Pacific, and (bottom) SE Atlantic. Frequency is shown on a logarithmic scale, and darker colors indicate more frequent occurrences.

have been shown to have more intense localized rain rates compared to nearby closed-cellular cloudiness regions (Stevens et al. 2005; Comstock et al. 2007; Wood et al. 2008). To account for this, we repeat the precipitation sensitivity analysis using areal-average rainrate measurements from the VOCALS-REx ship data at all times of day. In Fig. 11, we show the distributions of $\Delta \mathrm{CF}$ after $1 \mathrm{~h}(T+1 \mathrm{~h})$ and $3 \mathrm{~h}(T+3 \mathrm{~h})$ conditioned on the local time of day $(T=0$; Figs. 11a,b) and on the measured areal-average rain rate at $T=0$ (Figs. 11c,d). CF changes are clearly dependent on the diurnal cycle, with $\Delta \mathrm{CF}<0 \%$ mostly observed during the day and $\Delta \mathrm{CF}>0 \%$ overnight (Figs. 11a,b). In agreement with observations presented earlier in this paper, there are few data points that record large decreases in cloudiness overnight. There is a robust diurnal cycle of precipitation in the SE Pacific with a large maximum in precipitation area and rain rate occurring in the early morning hours (0200-0300 LT; Burleyson et al. 2013, their Fig. 9). If areal-average rain rate had a large influence on $\mathrm{CF}$, one would expect frequent occurrences of $\Delta \mathrm{CF}<0 \%$ near the $0200-0300$ LT precipitation peak. However, this is not observed. Further, Figs. 11c,d demonstrate that $\triangle \mathrm{CF}$ is poorly correlated to areal-average rain rate regardless of time of day, a consequence of precipitation often occurring in overcast conditions that may be more resistant to cloud breakup (Hall 2013). Most commonly, larger drizzle areas and higher arealaverage rain rates are associated with little to no change in CF (Figs. 10 and 11). Some of the largest decreases in $\mathrm{CF}$ occur in the afternoon, when there is hardly any precipitation present. There are a handful of cases of collocated high rain rates and cloud breakup on both 1and 3-h time scales, but a close examination of these data points shows that they occur more often near or after dawn. Only 4 out of 289 of the +1 -h samples and 9 out of 306 of the +3 -h samples with $\Delta \mathrm{CF}<-5 \%$ occurred between 1800 and 0600 LT. The evidence presented in this paper as well as in Burleyson and Yuter (2015) suggests that cloud breakup within many of the near dawn POC cases in the literature (Table 1) may be caused primarily by SW radiative effects rather than being primarily precipitation-induced cloud breakup.

\section{Seasonal and regional variability}

We show the month-to-month variability of net overnight $\mathrm{CF}$ changes on $3^{\circ} \times 3^{\circ}$ spatial scales in the left 

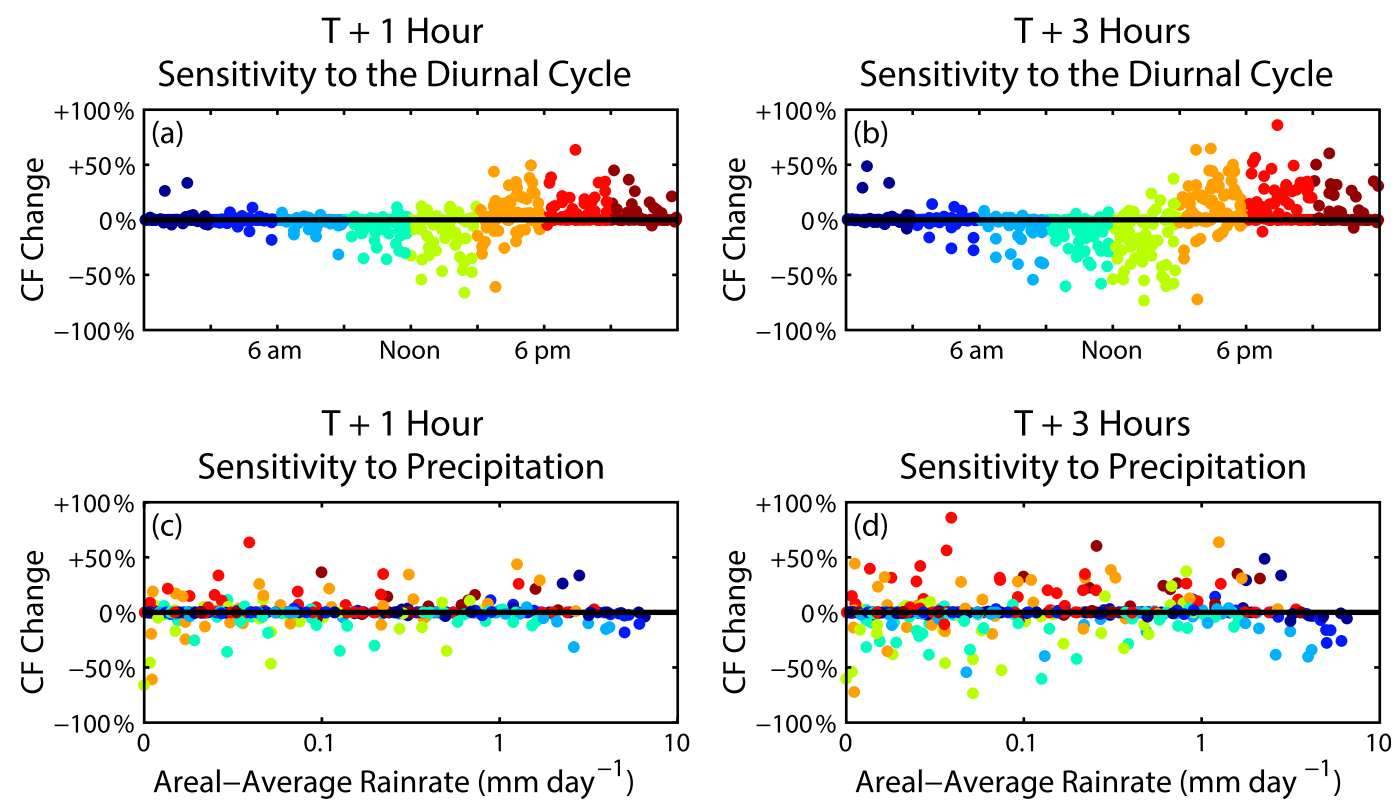

FIG. 11. The CF changes as a function of time of day and area-average rain rate from the NOAA R/V Ronald H. Brown cruises during VOCALS-REx. (top) Scatterplot of CF changes between local time on the $x$ axis and (a) $1 \mathrm{~h}$ later and (b) $3 \mathrm{~h}$ later. (bottom) The same data in each column replotted relative to areal-average rain rate. The $\mathrm{CF}$ is calculated over a moving $1^{\circ} \times 1^{\circ}$ box centered on the ship track. Area-average rain rates were measured by the $\mathrm{C}$-band radar on the ship. Each observation is color coded to distinguish the 3-h window in which it was collected.

column of Fig. 12. In the SE Pacific (Fig. 12d), the highest frequency of cloud breakup overnight occurs during June-August, where a net decrease $(\Delta \mathrm{CF}<$ $-15 \%$ and $-15 \%<\Delta \mathrm{CF}<-2 \%$ ) occurs $\sim 20 \%$ of the time. Most of the net decrease events are small $(-15 \%<\Delta \mathrm{CF}<-2 \%)$. The probability of observing large CF decreases overnight is less than 1 in 10 at any time during the year. Data from the SE Atlantic (Fig. 12g) also show an annual cycle with a broader peak in net decreasing CF that spans from April through September. Similar to the SE Pacific, the probability of observing large decreases in CF overnight is less than 1 in 13 throughout the year in the SE Atlantic. In the NE Pacific (Fig. 12a), the probability of observing large decreases in $\mathrm{CF}$ peaks in November and December, where it occurs in 1 out of every 6 overnight time series. The annual cycles in all three regions indicate that net overnight decreases are slightly more likely to occur just before the peak season of cloudiness within each region and are less likely to occur during the minimum cloudiness season. This is consistent with Fig. 6, which shows that net overnight $\mathrm{CF}$ decreases occur more frequently when $\mathrm{CF}$ at dusk is greater than $80 \%$, which rarely happens during the minimum cloudiness season.

Examining the distributions of precipitation area and EIS may provide some information on the environmental conditions that cause $\mathrm{CF}$ to decrease overnight. The drizzle area distributions in all three regions (Figs. 12b,e,h) show that $3^{\circ} \times 3^{\circ}$ areas with large increases in CF have slightly less drizzle (indicated by a higher frequency of drizzle areas smaller than $10 \%$ ) compared to areas in which $\mathrm{CF}$ decreases or has only small increases overnight. The $3^{\circ} \times 3^{\circ}$ boxes with neutral $\mathrm{CF}$ changes $(-2 \%<\Delta \mathrm{CF}<+2 \%)$ overnight tend to have larger drizzle areas. This is consistent with Fig. 10, which shows that $\Delta \mathrm{CF}$ over 1 and $3 \mathrm{~h}$ after the 0130 LT AMSR-E measurement is tightly clustered around $0 \%$ for larger drizzle area regions. The dominant signal in the drizzle area distributions is the overlap in drizzle area distributions for nights that had large decreases and small increases in CF. Many of the cases where $\mathrm{CF}$ decreased overnight had very little drizzle present at $0130 \mathrm{LT}$. The $3^{\circ} \times 3^{\circ}$ regions with drizzle areas larger than $25 \%$ were nearly equally likely to have net increases or net decreases in CF by dawn. In the NE Pacific and SE Atlantic, the EIS distributions (Figs. 12c,i) are similar on nights where CF increases or decreases overnight. This is somewhat expected as CF primarily correlates with stability on monthly and longer time scales (Klein and Hartmann 1993). EIS distributions in the SE Pacific are more variable among CF states (Fig. 12f). Overnight neutral CF cases are more likely to occur during periods of stronger inversions, and EIS has a broader distribution for large $\mathrm{CF}$ increases compared to the other overnight $\mathrm{CF}$ change categories.

Subtropical marine stratocumulus cloud decks are sometimes idealized as relatively simple cloud-topped 
(a)

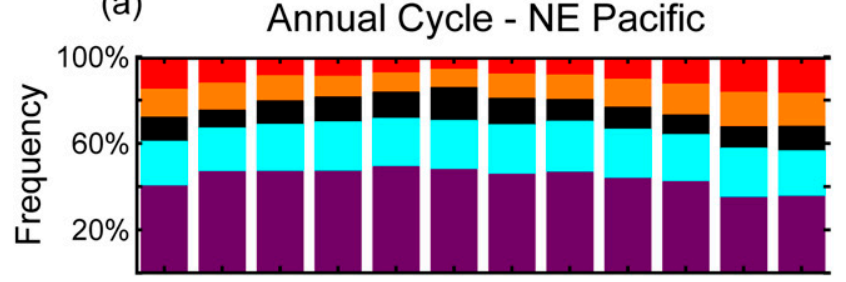

(d)

Annual Cycle - NE Pacific

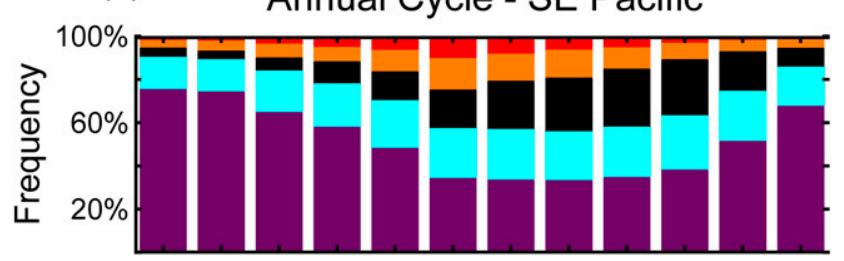

(g)
Annual Cycle - SE Pacific

Annual Cycle - SE Atlantic

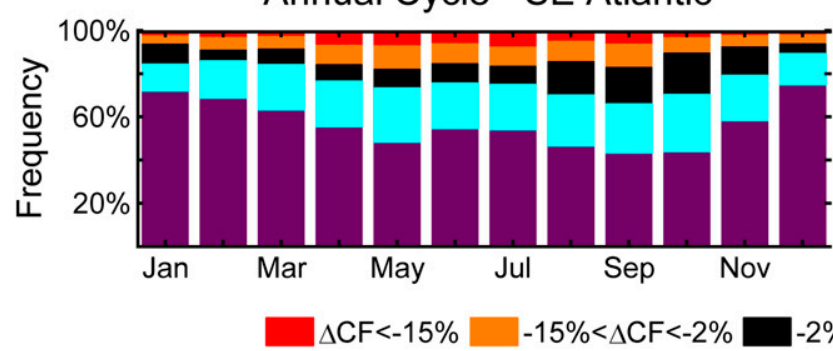

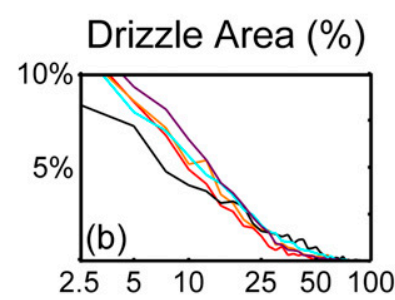

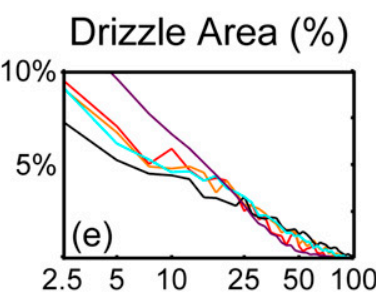

Drizzle Area (\%)

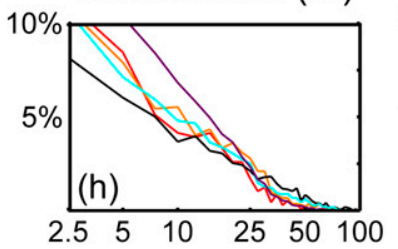

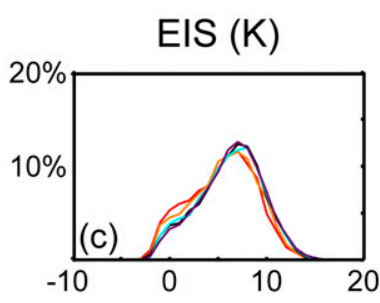

EIS (K)

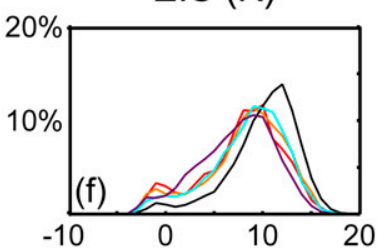

EIS (K)

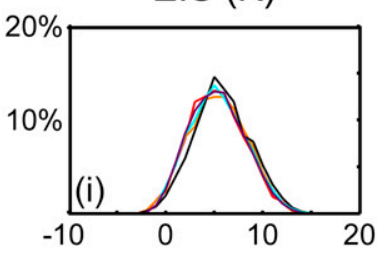

\footnotetext{
CF $<+2 \% \quad+2 \%<\Delta C F<+15 \% \quad \Delta \mathrm{CF}>+15 \%$
}

FIG. 12. (a),(d),(g) Monthly bar plots of the relative proportions of overnight time series with different net CF changes, (b),(e),(h) the associated drizzle area distributions, and (c),(f),(i) EIS distributions for all months combined. Results are shown for the (top) NE Pacific, (middle) SE Pacific, and (bottom) SE Atlantic. Frequencies in the bar plots are based on CFs in $3^{\circ} \times 3^{\circ}$ boxes aggregated for each region and month. EIS distributions are based on the closest 6-hourly reanalysis field. Drizzle areas are from the 0130 LT AMSR-E measurement and are for the subset of $3^{\circ} \times 3^{\circ}$ boxes that overlapped with individual AMSR-E orbit swaths. Color coding denotes large decreases in CF $(\Delta \mathrm{CF}<-15 \%$; red), small decreases in $\mathrm{CF}(-15 \%<\Delta \mathrm{CF}<-2 \%$; orange $)$, neutral CF changes $(-2 \%<\Delta \mathrm{CF}<+2 \%$; black $)$, small increases in $\mathrm{CF}(+2 \%<\Delta \mathrm{CF}<+15 \%$; cyan $)$, and large increases in $\mathrm{CF}(\Delta \mathrm{CF}>+15 \%$; purple).

boundary layer structures whose main sources of variation are "local": underlying SST (e.g., boundary layer height), inversion strength, aerosol concentration, and SW fluxes. The observed differences in diurnal characteristics among the stratocumulus clouds over the NE Pacific, SE Pacific, and SE Atlantic are in part related to these local factors but also are manifestations of different superpositions of larger-scale influences. The SE Pacific and SE Atlantic have diurnal CF characteristics that are more similar to each other than to the NE Pacific. These characteristics include the amplitude and seasonal variation of the diurnal cycle of CF (Fig. 4), sharper contrasts between $\mathrm{CF}$ diurnal variability toward the center of the cloud deck as compared to edges (Fig. 3), and the likelihood of large CF decreases overnight (Figs. 7, 8, and 12). The amplitude of the diurnal cycle warrants detailed study throughout the 24-h period, especially in the two Southern Hemisphere regions. The evening buildup in CF between 1800 and 0000 LT and the associated precipitation conditions were missed by aircraft during VOCALS-REx, which only flew nocturnal flights after midnight (Wood et al. 2011a). We suggest that the smaller seasonal variability in the CF diurnal cycle in the NE Pacific compared to the two Southern Hemisphere regions is related to stronger multiday-time-scale influences from the extratropical storm track and the ITCZ, which act to disturb the environment. The potential interactions between subtropical marine stratocumulus clouds and multiday influences, including midlatitude and tropical waves, warrant further study in all three regions.

\section{Conclusions}

In this analysis, we used observations of subtropical marine stratocumulus $\mathrm{CF}$ time series to identify the range of observed net changes in $\mathrm{CF}$ during the day and at night. We quantified the frequency and relative importance of cloud breakup overnight on $3^{\circ} \times 3^{\circ}$ spatial scales. The primary conclusions from our analysis are as follows:

1) Net decreases in CF during the night and increases during the day, which would be deviations from the 
basic diurnal cycle, occur infrequently. Very large localized decreases in $\mathrm{CF}$ overnight $(\mathrm{CF} \geq 90 \%$ sometime during the night and $\mathrm{CF}<60 \%$ at dawn), such as those that would result from the nocturnal formation of POCs, are outliers. These events occur only $1.5 \%, 1.6 \%$, and $3.3 \%$ of the time in the SE Pacific, SE Atlantic, NE Pacific, respectively.

2) Radiatively driven regional cloudiness area decreases during the day (median $\leq-5.7 \times 10^{5} \mathrm{~km}^{2}$ in the SE Pacific and SE Atlantic) represent a quarter or more of the annual-mean area of the stratocumulus cloud deck.

3) CF changes overnight on time scales of $1-3 \mathrm{~h}$ and spatial scales of $100-300 \mathrm{~km}$ show minimal sensitivity to either precipitation area or intensity. Many of the cases where CF had a net decrease overnight had little to no drizzle present at 0130 LT. Additionally, cases with more widespread drizzle areas and higher areal-average rain rates often had little to no change in $\mathrm{CF}$.

4) Each of the subtropical stratocumulus regions has distinct characteristics, but the SE Pacific and SE Atlantic are more similar to each other than to the NE Pacific. Variations in characteristics of the diurnal cycle, especially the amplitude and seasonto-season variations, are larger in the Southern Hemisphere regions than in the NE Pacific.

A major difference between our study and previous efforts is the large sample size (over 50000 day and night 12-h time series for each region) we generated by using eight years of satellite data. Although this study does not definitively quantify the frequency of nocturnal POCs (because these are lumped together with other nonPOC nocturnal decreases in $\mathrm{CF}$ ), it does provide evidence that the signature of their formation, large decreases in localized CF overnight resulting in a broken cloud field at dawn, occurs infrequently. When measured against the magnitude of cloud area breakup that occurs daily because of the radiatively forced diurnal cycle of $\mathrm{CF}$, instances of cloud breakup overnight that persist until dawn have a much smaller impact. In terms of controlling large-scale subtropical marine stratocumulus cloud area and the associated radiative balance, nocturnal POC decreases in cloudiness are relatively unimportant compared to the solar-forced diurnal and seasonal cycles.

The marine stratocumulus community's recent focus on studying aerosol-cloud-precipitation interactions within POCs has largely ignored the more common situation of heavy drizzle not being associated with nocturnal cloud breakup. This is akin to the observational bias called the "streetlight effect" (Freedman 2010), where one looks for what one is searching for where it is easiest to find. Our contention is not that precipitation cannot cause cloud breakup overnight, but rather that this does not represent the dominant behavior of the stratocumulus-topped boundary layer system. A large number of the POC formation events discussed in the literature occur near or after dawn. Once the sun is up, it is illogical for cloud breakup to be solely attributed to precipitation. Future work on POCs would benefit from focus on those that are truly nocturnal (i.e., occurring well before dawn) so that potentially confounding SW flux factors can be eliminated from attribution.

Acknowledgments. Special thanks are due to Simon de Szoeke, David Mechem, Matthew Miller, Matthew Parker, and Walter Robinson for their feedback and technical support. This work was funded by National Oceanic and Atmospheric Administration (NOAA)/ Climate Program Office (CPO)/Climate Prediction Program for the Americas (CPPA) Grant GC09-252b, Department of Energy Atmospheric Systems Research Grant DE SC0006701, and National Aeronautics and Space Administration Grant NNX11AE98G. The lead author was supported in part by NASA Earth and Space Science Fellowship NNX10AP43H. The Pacific Northwest National Laboratory is operated for DOE by Battelle Memorial Institute under Contract DE-AC06-76RLO 1830.

\section{REFERENCES}

Abel, S. J., D. N. Walters, and G. Allen, 2010: Evaluation of stratocumulus cloud precipitation in the Met Office forecast model during VOCALS-REx. Atmos. Chem. Phys., 10, 10 541-10 559, doi:10.5194/acp-10-10541-2010.

Albrecht, B. A., 1989: Aerosols, cloud microphysics, and fractional cloudiness. Science, 245, 1227-1230, doi:10.1126/ science.245.4923.1227.

Allen, G., and Coauthors, 2013: Gravity-wave induced perturbations in marine stratocumulus. Quart. J. Roy. Meteor. Soc., 139, 32-45, doi:10.1002/qj.1952.

Atkinson, B. W., and J. W. Zhang, 1996: Mesoscale shallow convection in the atmosphere. Rev. Geophys., 34, 403-431, doi:10.1029/ 96RG02623.

Berner, A. H., C. S. Bretheron, R. Wood, and A. Muhlbauer, 2013: Marine boundary layer cloud regimes and POC formation in an LES coupled to a bulk aerosol scheme. Atmos. Chem. Phys., 13, 12 549-12 572, doi:10.5194/acp-13-12549-2013.

Betts, A. K., 1990: Diurnal variation of California coastal stratocumulus from two days of boundary layer soundings. Tellus, 42A, 302-304, doi:10.1034/j.1600-0870.1990.t01-1-00007.x.

Bretherton, C. S., and M. C. Wyant, 1997: Moisture transport, lower-tropospheric stability, and decoupling of cloud-topped boundary layers. J. Atmos. Sci., 54, 148-167, doi:10.1175/ 1520-0469(1997)054<0148:MTLTSA>2.0.CO;2.

_ _, and Coauthors, 2004: The EPIC 2001 stratocumulus study. Bull. Amer. Meteor. Soc., 85, 976-977, doi:10.1175/ BAMS-85-7-967. 
Burleyson, C. D., 2013: Environmental controls on stratocumulus cloud fraction. Ph.D. dissertation, North Carolina State University, 193 pp. [Available online at http://repository.lib.ncsu. edu/ir/bitstream/1840.16/9037/1/etd.pdf.]

— cloud fraction variability. J. Appl. Meteor. Climatol., doi:10.1175/ JAMC-D-14-0178.1, in press.

- S. P. de Szoeke, S. E. Yuter, M. Wilbanks, and W. A. Brewer, 2013: Ship-based observations of the diurnal cycle of southeast Pacific marine stratocumulus clouds and precipitation. J. Atmos. Sci., 70, 3876-3894, doi:10.1175/JAS-D-13-01.1.

Comstock, K. K., C. S. Bretherton, and S. E. Yuter, 2005: Mesoscale variability and drizzle in southeast Pacific stratocumulus. J. Atmos. Sci., 62, 3792-3807, doi:10.1175/JAS3567.1.

- S. E. Yuter, R. Wood, and C. S. Bretherton, 2007: The threedimensional structure and kinematics of drizzling stratocumulus. Mon. Wea. Rev., 135, 3767-3784, doi:10.1175/2007MWR1944.1.

de Szoeke, S. P., S. E. Yuter, D. Mechem, C. W. Fairall, C. D. Burleyson, and P. Zuidema, 2012: Observations of stratocumulus and their effect on the eastern Pacific surface heat budget along $20^{\circ}$ S. J. Climate, 25, 8542-8567, doi:10.1175/ JCLI-D-11-00618.1.

Duynkerke, P. G., 1989: The diurnal variation of a marine stratocumulus cloud: A model sensitivity study. Mon. Wea. Rev., 117, 1710-1725, doi:10.1175/1520-0493(1989)117<1710: TDVOAM $>2.0$.CO;2.

ECMWF, 2009: ERA-Interim project. National Center for Atmospheric Research Computational and Information Systems Laboratory Research Data Archive. [Available online at http://rda.ucar.edu/datasets/ds627.0.]

Feingold, G., I. Koren, H. Wang, H. Xue, and W. A. Brewer, 2010: Precipitation-generated oscillations in open cellular cloud fields. Nature, 466, 849-852, doi:10.1038/nature09314.

Freedman, D. H., 2010: Wrong: Why Experts Keep Failing Us. Little, Brown and Company, 304 pp.

George, R. C., and R. Wood, 2010: Subseasonal variability of low cloud radiative properties. Atmos. Chem. Phys., 10, 40474063, doi:10.5194/acp-10-4047-2010.

Ghate, V. P., B. A. Albrecht, C. W. Fairall, and R. A. Weller, 2009: Climatology of surface meteorology, surface fluxes, cloud fraction, and radiative forcing over the southeast Pacific from buoy observations. J. Climatol., 22, 5527-5540, doi:10.1175/ 2009JCLI2961.1.

Hall, A. M., 2013: Lifecycle characteristics of marine stratocumulus precipitation in the southeast Pacific. M.S. thesis, Dept. of Marine, Earth, and Atmospheric Sciences, North Carolina State University, $88 \mathrm{pp}$. [Available online at http://repository. lib.ncsu.edu/ir/bitstream/1840.16/9307/1/etd.pdf.]

Hartmann, D. L., M. E. Ockert-Bell, and M. L. Michelson, 1992: The effect of cloud type on Earth's energy balance: Global analysis. J. Climate, 5, 1281-1304, doi:10.1175/1520-0442(1992)005<1281: TEOCTO $>2.0 . \mathrm{CO} ; 2$.

James, D. G., 1959: Observations from aircraft of temperatures and humidities near stratocumulus clouds. Quart. J. Roy. Meteor. Soc., 85, 120-130, doi:10.1002/qj.49708536405.

Klein, S. A., and D. L. Hartmann, 1993: The seasonal cycle of low stratiform clouds. J. Climate, 6, 1587-1606, doi:10.1175/ 1520-0442(1993)006<1587:TSCOLS > 2.0.CO;2.

_, _ _ and J. R. Norris, 1995: On the relationships among low-cloud structure, sea surface temperature, and atmospheric circulations in the summertime northeast Pacific. J. Climate, 8, 1140-1155, doi:10.1175/1520-0442(1995)008<1140: OTRALC $>2.0 . \mathrm{CO} ; 2$.
Koren, I., and G. Feingold, 2013: Adaptive behavior of marine clouds. Sci. Rep., 3, 2507, doi:10.1038/srep02507.

Leon, D. C., Z. Wang, and D. Liu, 2008: Climatology of drizzle in marine boundary layer clouds based on 1 year of data from CloudSat and Cloud-Aerosol Lidar and Infrared Pathfinder Satellite Observations (CALIPSO). J. Geophys. Res., 113, D00A14, doi:10.1029/2008JD009835.

Lilly, D., 1968: Models of cloud-topped mixed layers under a strong inversion. Quart. J. Roy. Meteor. Soc., 94, 292-309, doi:10.1002/ qj.49709440106.

Manabe, S., and R. F. Strickler, 1964: Thermal equilibrium of the atmosphere with a convective adjustment. J. Atmos. Sci., 21, 361-385, doi:10.1175/1520-0469(1964)021<0361: TEOTAW $>2.0 . \mathrm{CO} ; 2$.

Mechem, D. B., S. E. Yuter, and S. P. de Szoeke, 2012: Thermodynamic and aerosol controls in southeast Pacific stratocumulus. J. Atmos. Sci., 69, 1250-1266, doi:10.1175/ JAS-D-11-0165.1.

Mechoso, C. R., and Coauthors, 2014: Ocean-cloud-atmosphereland interactions in the southeastern Pacific: The VOCALS Program. Bull. Amer. Meteor. Soc., 95, 357-375, doi:10.1175/ BAMS-D-11-00246.1.

Medeiros, B., D. L. Williamson, C. Hannay, and J. G. Olson, 2012: Southeast Pacific stratocumulus in the Community Atmosphere Model. J. Climate, 25, 6175-6192, doi:10.1175/ JCLI-D-11-00503.1.

Miller, M. A., and S. E. Yuter, 2013: Detection and characterization of heavy drizzle cells within subtropical marine stratocumulus using AMSR-E $89-\mathrm{GHz}$ passive microwave measurements. Atmos. Meas. Tech., 6, 1-13, doi:10.5194/amt-6-1-2013.

Muhlbauer, A., I. L. McCoy, and R. Wood, 2014: Climatology of stratocumulus cloud morphologies: Microphysical properties and radiative effects. Atmos. Chem. Phys., 14, 6695-6716, doi:10.5194/acp-14-6695-2014.

Myers, T. A., and J. R. Norris, 2013: Observational evidence that enhanced subsidence reduces subtropical marine boundary layer cloudiness. J. Climate, 26, 7507-7524, doi:10.1175/ JCLI-D-12-00736.1.

Nicholls, S., 1984: The dynamics of stratocumulus: Aircraft observations and comparisons with a mixed layer model. Quart. J. Roy. Meteor. Soc., 110, 783-820, doi:10.1002/qj.49711046603.

Pincus, R., and M. B. Baker, 1994: Effect of precipitation on the albedo susceptibility of clouds in the marine boundary layer. Nature, 372, 250-252, doi:10.1038/372250a0.

Platnick, S., M. D. King, S. A. Ackerman, W. P. Menzel, B. A. Baum, and R. A. Frey, 2003: The MODIS cloud products: Algorithms and examples from Terra. IEEE Trans. Geosci. Remote Sens., 41, 459-473, doi:10.1109/TGRS.2002.808301.

Rossow, W. B., and R. A. Schiffer, 1991: ISCCP cloud data products. Bull. Amer. Meteor. Soc., 72, 2-20, doi:10.1175/ 1520-0477(1991)072<0002:ICDP>2.0.CO;2.

Rozendaal, M., C. B. Leovy, and S. A. Klein, 1995: An observational study of diurnal variations of marine stratiform cloud. J. Climate, 8, 1795-1809, doi:10.1175/1520-0442(1995)008<1795: AOSODV $>2.0 . \mathrm{CO} ; 2$.

Savic-Jovcic, V., and B. Stevens, 2008: The structure and mesoscale organization of precipitating stratocumulus. J. Atmos. Sci., 65, 1587-1605, doi:10.1175/2007JAS2456.1.

Sharon, T. M., B. A. Albrecht, H. H. Jonsson, P. Minnis, M. M. Khaiyer, T. M. van Reken, J. Seinfeld, and R. Flagan, 2006: Aerosol and cloud microphysical characteristics of rifts and gradients in maritime stratocumulus clouds. J. Atmos. Sci., 63, 983-997, doi:10.1175/JAS3667.1. 
Stephens, G. L., and Coauthors, 2002: The CloudSat mission and the A-Train: A new dimension of space-based observations of clouds and precipitation. Bull. Amer. Meteor. Soc., 83, 17711790, doi:10.1175/BAMS-83-12-1771.

Stevens, B., and Coauthors, 2003: Dynamics and chemistry of marine stratocumulus-DYCOMS-II. Bull. Amer. Meteor. Soc., 84, 579-593, doi:10.1175/BAMS-84-5-579.

, G. Vali, K. Comstock, R. Wood, M. VanZanten, P. H. Austin, C. S. Bretherton, and D. H. Lenschow, 2005: Pockets of open cells (POCs) and drizzle in marine stratocumulus. Bull. Amer. Meteor. Soc., 86, 51-57, doi:10.1175/BAMS-86-1-51.

Terai, C. R., 2011: Drizzle and the aerosol indirect effect in marine stratocumulus. M.S. thesis, Dept. of Atmospheric Sciences, University of Washington, $91 \mathrm{pp}$.

- C. S. Bretherton, R. Wood, and G. Painter, 2014: Aircraft observations of pockets of open cells sampled during VOCALS-REx. Atmos. Chem. Phys. Discuss., 14, $8287-$ 8332, doi:10.5194/acpd-14-8287-2014.

Toniazzo, T., S. J. Abel, R. Wood, C. R. Mechoso, G. Allen, and L. C. Shaffrey, 2011: Large-scale and synoptic meteorology in the south-east Pacific during the observations campaign VOCALS-REx in austral spring 2008. Atmos. Chem. Phys., 11, 4977-5009, doi:10.5194/acp-11-4977-2011.

Turton, J. D., and S. Nicholls, 1987: A study of the diurnal variation of stratocumulus using a mixed layer model. Quart. J. Roy. Meteor. Soc., 113, 969-1009, doi:10.1002/qj.49711347712.

vanZanten, M. C., and B. Stevens, 2005: Observations of the structure of heavily precipitating marine stratocumulus. J. Atmos. Sci., 62, 4327-4342, doi:10.1175/JAS3611.1.

Wang, H., and G. Feingold, 2009: Modeling mesoscale cellular structures and drizzle in marine stratocumulus. Part I: Impact of drizzle on the formation and evolution of open cells. J. Atmos. Sci., 66, 3237-3256, doi:10.1175/2009JAS3022.1.

Wentz, F. J., and T. Meissner, 2000: AMSR ocean algorithm, version 2. Remote Sensing Systems Algorithm Theoretical Basis Doc. 121599A-1, 66 pp.

Wilbanks, M. C., 2013: Near surface density currents observed in the southeast Pacific stratocumulus-topped marine boundary layer. M.S. thesis, Dept. of Marine, Earth, and Atmospheric Sciences, North Carolina State University, 163 pp. [Available online at http://repository.lib.ncsu.edu/ir/bitstream/1840.16/ 8756/1/etd.pdf.]

Wood, R., 2012: Stratocumulus clouds. Mon. Wea. Rev., 140, 2373 2423, doi:10.1175/MWR-D-11-00121.1.

- and C. S. Bretherton, 2004: Boundary layer depth, entrainment, and decoupling in the cloud-capped subtropical and tropical marine boundary layer. J. Climate, 17, 3576-3588, doi:10.1175/1520-0442(2004)017<3576:BLDEAD>2.0.CO;2.

- and —, 2006: On the relationship between stratiform low cloud cover and lower tropospheric stability. J. Climate, 19, 6425-6432, doi:10.1175/JCLI3988.1.

— , and D. L. Hartmann, 2006: Spatial variability of liquid water path in marine low clouds: The importance of mesoscale cellular convection. J. Climate, 19, 1748-1764, doi:10.1175/ JCLI3702.1.

- K. K. Comstock, C. S. Bretherton, C. Cornish, J. Tomlinson, D. R. Collins, and C. W. Fairall, 2008: Open cellular structure in marine stratocumulus sheets. J. Geophys. Res., 113, D12207, doi:10.1029/2007JD009371.

, and Coauthors, 2011a: The VAMOS Ocean-CloudAtmosphere-Land Regional Experiment (VOCALS-REx): Goals, platforms, and field operations. Atmos. Chem. Phys., 11, 627-654, doi:10.5194/acp-11-627-2011.

C. S. Bretherton, D. Leon, A. D. Clarke, P. Zuidema, G. Allen, and H. Coe, 2011b: An aircraft case study of the spatial transition from closed to open mesoscale cellular convection over the Southeast Pacific. Atmos. Chem. Phys., 11, 2341-2370, doi:10.5194/acp-11-2341-2011.

Wyant, M. C., and Coauthors, 2010: The PreVOCA experiment: Modeling the lower troposphere in the southeast Pacific. Atmos. Chem. Phys., 10, 4757-4744, doi:10.5194/acp-10-4757-2010.

—_, and Coauthors, 2014: Global and regional modeling of marine boundary layer clouds and aerosols in the marine boundary layer during VOCALS: The VOCA intercomparison. Atmos. Chem. Phys. Discuss., 14, 65376587, doi:10.5194/acpd-14-6537-2014.

Xiao, H., C.-M. Wu, and C. R. Mechoso, 2011: Buoyancy reversal, decoupling and the transition from stratocumulus to shallow cumulus topped marine boundary layers. Climate Dyn., 37, 971-984, doi:10.1007/s00382-010-0882-3.

Xie, P., and P. A. Arkin, 1998: Global monthly precipitation estimates from satellite-observed outgoing longwave radiation. J. Climate, 11, 137-164, doi:10.1175/1520-0442(1998)011<0137: GMPEFS $>2.0 . \mathrm{CO} ; 2$.

Zhang, Y., B. Stevens, B. Medeiros, and M. Ghil, 2009: Lowcloud fraction, lower-tropospheric stability, and largescale divergence. J. Climate, 22, 4827-4844, doi:10.1175/ 2009JCLI2891.1.

Zuidema, P., D. Painemal, S. de Szoeke, and C. Fairall, 2009: Stratocumulus cloud-top height estimates and their climatic implications. J. Climate, 22, 4652-4666, doi:10.1175/ 2009JCLI2708.1 